\title{
Physiological and pathophysiological functions of the ecto-nucleotide pyrophosphatase/phosphodiesterase family
}

\author{
James W. Goding ${ }^{\mathrm{a}}$, Bert Grobben ${ }^{\mathrm{b}}$, Herman Slegers ${ }^{\mathrm{b}, *}$ \\ ${ }^{a}$ Department of Pathology and Immunology, Monash Medical School, Monash University, Prahran 3181, Victoria, Australia \\ ${ }^{\mathrm{b}}$ Department of Biomedical Sciences, Cellular Biochemistry, University of Antwerp, Universitaire Instelling Antwerpen, \\ Universiteitplein 1, B-2610 Antwerpen-Wilrijk, Belgium
}

Received 6 February 2003; received in revised form 20 March 2003; accepted 3 April 2003

\begin{abstract}
The ecto-nucleotide pyrophosphatase/phosphodiesterase (E-NPP) multigene family contains five members. NPP1-3 are type II transmembrane metalloenzymes characterized by a similar modular structure composed of a short intracellular domain, a single transmembrane domain and an extracellular domain containing a conserved catalytic site. The short intracellular domain of NPP1 has a basolateral membrane-targeting signal while NPP3 is targeted to the apical surface of polarized cells. NPP4-5 detected by database searches have a predicted type I membrane orientation but have not yet been functionally characterized.

E-NPPs have been detected in almost all tissues often confined to specific substructures or cell types. In some cell types, NPP1 expression is constitutive or can be induced by TGF- $\beta$ and glucocorticoids, but the signal transduction pathways that control expression are poorly documented.

NPP1-3 have a broad substrate specificity which may reflect their role in a host of physiological and biochemical processes including bone mineralization, calcification of ligaments and joint capsules, modulation of purinergic receptor signalling, nucleotide recycling, and cell motility. Abnormal NPP expression is involved in pathological mineralization, crystal depositions in joints, invasion and metastasis of cancer cells, and type 2 diabetes.

In this review we summarize the present knowledge on the structure and the physiological and biochemical functions of E-NPP and their contribution to the pathogenesis of diseases.
\end{abstract}

(C) 2003 Elsevier Science B.V. All rights reserved.

Keywords: Nucleotide pyrophosphatase; Bone mineralization; Purinergic receptor signalling; Cell motility; Type 2 diabetes

\section{Introduction}

Extracellular nucleotide hydrolysis was originally believed to be a straightforward process in which individual enzymes hydrolyze ATP (ecto-ATPase), ADP (ecto-ATPase, ecto-ATPDase) and AMP (ecto-5'-nucleotidase) but recent work has revealed a more complex picture involving several families of ecto-nucleotidases. These enzymes appear to have multiple roles in extracellular nucleotide metabolism and in the regulation of nucleotide-based intercellular signalling.

This review summarizes the properties of a family of ecto-nucleotide pyrophosphatases/phosphodiesterases (E-

\footnotetext{
* Corresponding author. Tel.: +32-3-8202306; fax: +32-3-8202248.

E-mail address: slegers@uia.ua.ac.be (H. Slegers).
}

NPPs) that has been identified over the last 10 years, which hydrolyzes $5^{\prime}$-phosphodiester bonds in nucleotides and their derivatives, resulting in the release of $5^{\prime}$-nucleotide monophosphates [1, and references therein]. So far, three members (NPP1-3), characterized by a similar modular structure, have been cloned and intensively studied. Based on sequence homology with the catalytic site of E-NPPs, NPP4 and NPP5 have been identified as additional members of the E-NPP family, but little is known concerning their catalytic activity.

Current evidence suggests that E-NPPs have multiple and largely related physiological roles, including nucleotide recycling, modulation of purinergic receptor signalling, regulation of extracellular pyrophosphate levels, stimulation of cell motility, and possible roles in regulation of insulin receptor (IR) signalling and activity of ecto-kinases. Aberrant expression of E-NPPs has been demonstrated in several 
pathologies including bone mineralization dysfunction, cell motility and migration, angiogenesis, tumor cell invasion, and type 2 diabetes, but the underlying mechanisms largely remain to be determined.

Recently, the substrate range of the E-NPP family has been broadened by showing that autotaxin (NPP2) hydrolyzes lysophosphatidylcholine (LPC) into lysophosphatidic acid (LPA), which is known to activate G protein-coupled receptors [2,3]. This exciting observation provides a convincing mechanistic link between enzyme expression and control of cell motility, and illustrates the basic principle that the ultimate action of these enzymes in physiological and pathological processes is the outcome of both expression levels and local availability of substrates.

\section{The E-NPP multigene family}

E-NPPs belong to a multigene family that currently contains five members. The E-NPPs have been discovered and rediscovered independently by several different laboratories, resulting in a confusing nomenclature (Table 1). Throughout this review, we will use the current nomenclature by which the E-NPPs are numbered according to their order of discovery (NPP1-5). A phylogenetic tree shows the relationships among the members of the E-NPP family (Fig. 1).

\subsection{Domain structure and catalytic mechanism}

NPP1-3 are type II transmembrane glycoproteins characterized by a similar modular structure composed of a short amino-terminal intracellular domain, a single transmembrane domain, and a large extracellular domain [1]. The latter domain contains two somatomedin B-like motifs, a conserved catalytic site, a nuclease-like sequence, and a putative C-terminal 'EF-hand' motif, although the latter is controversial and has not been directly demonstrated. NPP1 and NPP2 are disulfide-bound homodimers whereas NPP3 is monomeric. In contrast, NPP4-5 have a predicted type I transmembrane orientation with a short intracellular carboxy-terminal domain, a significantly smaller extracellular domain as compared to NPP1-3 and an unknown oligomeric structure. The extracellular domain only contains a phosphodiesterase motif.

The short intracellular N-terminal (NPP1-3) and C-terminal (NPP4-5) domains show a striking lack of conservation between the different isoforms. NPP1 has a longer intracellular domain than NPP2 and NPP3. The human and rat/mouse NPP1domains differ in length and contain 76 and 58 amino acids, respectively [4], while the NPP2 and NPP3 domains contain only 10 and 22 amino acids, respectively [1]. Computation of the secondary structure probabilities http://bmerc-www.bu.edu/psa) predicts the presence of four loop-connected short helices in the N-terminal domain of human NPP1 and one or two sequential helices in rat and mouse NPP1 (Slegers, unpublished data). The N-terminal sequence of NPP1 and NPP3 contains information for the specific membrane targeting in polarized cells. NPP1 is localized at the basolateral membrane of hepatocytes although it is not endocytosed, whereas NPP3 is targeted apically [5]. The basolateral signal sequence has been identified as a di-leucine motif (AAASLLAP) localized in the intracellular domain [6]. Mutation of this motif targets NPP1 to the apical membrane. In addition, incorporation of the di-leucine motif into the cytoplasmic domain of NPP3 results in its retention in the basolateral membrane. When six residues upstream of the di-leucine motif are deleted, NPP1 is sequestered intracellularly, indicating that sequences flanking the di-leucine motif are also important. The

Table 1

Members of the E-NPP family

\begin{tabular}{|c|c|c|c|c|}
\hline \multirow[t]{2}{*}{ Name/gene } & \multirow[t]{2}{*}{ Historical names } & \multicolumn{2}{|l|}{ Proposed function } & \multirow[t]{2}{*}{ References } \\
\hline & & Physiological & Pathological & \\
\hline NPP1 & $\begin{array}{l}\text { PC-1, PC. } 1, \text { MAFP, } \\
\text { NPPase, NPP } \gamma\end{array}$ & $\begin{array}{l}\text { Nucleotide recycling, } \\
\text { calcification }\end{array}$ & $\begin{array}{l}\text { OPLL, CPPD disease, } \\
\text { type } 2 \text { diabetes }\end{array}$ & {$[31,35,197-199$} \\
\hline enppl (6q22-23) & $P D N P 1, N P P S, P c a-1$ & & & \\
\hline NPP2 & Autotaxin, PD-1 $\alpha, \mathrm{NPP} \alpha$ & $\begin{array}{l}\text { Calcification, regulation } \\
\text { of cell motility }\end{array}$ & $\begin{array}{l}\text { Increased tumor motility } \\
\text { and invasion, angiogenesis }\end{array}$ & {$[25,42,49,199]$} \\
\hline епрр2 (8q2) & $P D N P 2$ & & & \\
\hline $\begin{array}{l}\text { NPP3 } \\
\text { enpp3 (6q22) }\end{array}$ & $\begin{array}{l}\text { gp130 }{ }^{\mathrm{RB} 13-6}, \mathrm{~B} 10, \mathrm{PD}-\mathrm{I} \beta, \mathrm{NPP} \beta \\
\text { PDNP3, Pdnрпо }\end{array}$ & Nucleotide recycling & Increased tumor invasion & {$[5,10,37,50,199]$} \\
\hline $\begin{array}{l}\text { NPP4 } \\
\text { enpp4 (6p12.3) }\end{array}$ & - & - & - & {$[11]$} \\
\hline $\begin{array}{l}\text { NPP5 } \\
\text { enpp5 }(6 \mathrm{p} 11.2-21.1)\end{array}$ & - & - & - & {$[11]$} \\
\hline
\end{tabular}

Nomenclature of E-NPP family members. This table provides an overview of the historical names and the proposed functions of E-NPPs in physiological processes and pathological conditions. OPLL: ossification of the posterior longitudinal ligament of the spine; CPPD: calcium pyrophosphate dihydrate; PC-1: plasma-cell differentiation antigen-1; MAFP: major aFGF-stimulated protein; NPP: nucleotide pyrophosphatase; PDNP: phosphodiesterase nucleotide pyrophosphatase; PD-I: phosphodiesterase I.

Splice variants are indicated by Greek suffixes. The encoding gene is designated enpp followed by the same numerical suffix as the protein [200]. 


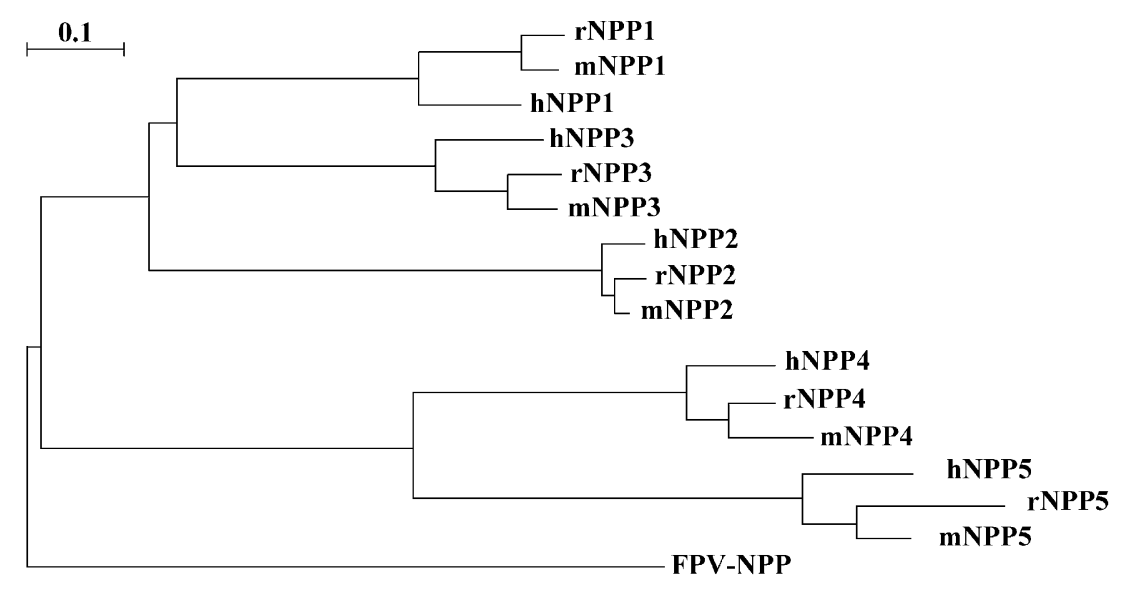

Fig. 1. Phylogenetic tree of E-NPPs. The relationship within the E-NPP family is deduced from sequence alignments. NPP1 displays a mean (human, mouse, rat) amino acid identity of about $42 \%$ and $49 \%$ with NPP2 and NPP3, respectively, and NPP2 has a mean amino acid identity of $45 \%$ with NPP3. The mean amino acid identity between NPP4 and NPP5 is 43\% but is much lower with NPP1-3 (17-25\%). A viral homologue of NPP (FP-PC1) encoded by the Fowlpox virus has a mean $34 \%$ amino acid identity with mammalian NPP1. Although originally designated FP-PC1, it also has about 33\% amino acid identity with both NPP2 and NPP3. The amino acid identity with NPP4 and NPP5 is only about $15 \%$. Protein sequences are retrieved from GenBank and aligned with CLUSTALX. h: human; m: mouse; r: rat. hNPP1: AAF36094; hNPP2: BAA08260; hNPP3: AAC51813; hNPP4: BAA74902; hNPP5: CAB56566; rNPP1: AF320054; rNPP2: BAA05910; rNPP3: BAA06333; rNPP4: XP_236955; rNPP5: XP_236956; mNPP1: AF339910; mNPP2: AF123542; mNPP3: constructed from mouse ESTs BF123542, BF108406, AAHO5527, BE376939, AW318979; mNPP4:AAH27749; mPP5: AAH11294; Fowlpox virus: AAF44374. The bar indicates 0.1 substitution per site.

signals responsible for apical localization and those that distinguish endocytosis from basolateral targeting remain to be determined [6].

The extracellular domain of NPP1-3 contains two somatomedin B-like repeats proximal to the plasma membrane. These cysteine-rich tandem repeats are similar to the somatomedin B domains of vitronectin, the eight cysteine residues being in homologous positions in the sequence suggesting a linear uncrossed pattern of disulfide bonds [7]. These domains appear to contribute to the correct processing and folding of NPPs, because their deletion from NPP1 results in retention of the enzyme in the endoplasmic reticulum (ER) (Belli and Goding, unpublished data).

NPP1-3 are classified as alkaline ecto-nucleotide pyrophosphatase [EC 3.6.1.9]/phosphodiesterase I [EC 3.1.4.1] [8-10] and catalyze the hydrolysis of pyrophosphate and phosphodiester bonds in a two-step mechanism in which two essential divalent metal ions are required for the formation of a nucleotidylated active-site threonine intermediate and the subsequent release of nucleoside $5^{\prime}$-monophosphate $[1,11]$. A putative 'EF-hand' $\mathrm{Ca}^{2+}$-binding motif (DXD/NXDGXXD) located in the C-terminal part of the extracellular domain is essential for the catalytic activity of NPP1 and NPP3 [1,12]. However, deletion of this motif in NPP2 only slightly affects its enzymatic activity and has no effect on its motility stimulating property, indicating that binding of the required divalent ions is not mediated by this region in NPP2 [13]. A structural model of the conserved catalytic site and a schematic overview of the catalytic cycle have been published by Gijsbers et al. [11], who also commented that the putative 'EF-hand' motif did not satisfy the structural criteria derived from proteins in which this motif is functional in $\mathrm{Ca}^{2+}$ binding.
The catalytic activity of E-NPPs is inhibited 'in vitro' by the glycosaminoglycans heparin, heparan sulfate, and a variety of other substances including imidazole, 2-mercaptoethanol, dithiothreitol, diethylpyrocarbonate, and metal ion-chelating agents $[11,14-16]$. At present, no physiological inhibitors of E-NPPs have been identified that act 'in vivo'.

Radioactive labeling of the active site threonine is observed upon incubation of purified NPP1 and NPP2 with $\left[\gamma^{32} \mathrm{P}\right]-$ and $\left[\alpha-{ }^{32} \mathrm{P}\right]-\mathrm{ATP}[15,17-20]$. The labeling represents formation of catalytic pyrophosphatase intermediates. At low ATP concentration, autophosphorylation of the enzyme has been observed that inhibits the enzymatic activity and is proposed to be an autoregulatory mechanism reversed upon addition of nucleotides to a concentration exceeding $5 \mu \mathrm{M}$ [15]. This autophosphorylation is a reflection of an intrinsic alkaline phosphatase activity resulting in the formation of a covalent phospho-intermediate [11]. Claims that NPP1 has protein kinase activity are controversial and have not been confirmed [18].

NPP1-5 contain 4 to 10 putative N-glycosylation sites (Asn-X-Ser/Thr). The glycans constitute up to $15 \mathrm{kD}$ of their molecular weight $[10,21]$, but as is the case for most $\mathrm{N}$ linked glycans, their function remains poorly understood. They may contribute to correct transport of E-NPPs to the plasma membrane but are not necessary for the apical targeting of NPP3, nor are they required for the motility stimulating property of NPP2 $[22,23]$.

Active soluble forms of NPP1-3 have been described in serum and conditioned medium [16,21,24-27]. NPP2 and NPP3 are cleaved outside the transmembrane region, generating a catalytic active soluble fragment of $125 \mathrm{kD}$ that includes the somatomedin B domains and the nuclease-like 
domain [24-26]. Human NPP1 transfected in COS 7 cells is cleaved close to the transmembrane domain, generating an active soluble enzyme with $\mathrm{K}^{113} \mathrm{EVKS} .$. as N-terminal sequence [16]. It is not clear whether these soluble NPPs represent alternative splice products or have been generated by proteolytic cleavage, and their physiological significance, if any, is currently unknown.

\subsection{Tissue distribution}

NPP1-3 have been detected in almost all tissues [1] although individual isoforms are usually confined to specific substructures and/or cell types [9,28-30]. In addition, NPP members have been localized in different cellular compartments and are differentially targeting to plasma membranes of polarized cells, suggesting specific physiological functions of NPPs in cells and tissues.

NPP1 was originally discovered on the surface of mouse B-lymphocytes by Takahashi et al. [31] as the plasma cell differentiation antigen ( $\mathrm{PC}-1)$. In mice, expression is high on antibody-secreting plasma cells (typically less than $1 \%$ of splenic lymphocytes), but very low or absent from immature and mature T- and B-lymphocytes. Distribution of NPP1 in human lymphocytes has been much less intensively studied. Expression is low or absent from most human T- or Blymphocytes, although it can be up-regulated upon activation of human T-cells [32]. Little is known concerning expression of NPP1 on human plasma cells. Human NPP1 is highly expressed in bone and cartilage cells with intermediate expression in heart, liver, placenta, and testis. In addition, NPP1 is also present on the distal convoluted tubules of the kidney, epithelium of salivary gland ducts, brain capillary endothelium, and the epididymis [28,3337]. No expression of NPP1 has been detected in neurons and glial cells, although it has been detected in rat C6 glioma cells [38].

NPP2 was discovered as an autocrine motility factor (autotaxin, NPP $2 \alpha$ ) in the conditioned medium of the human melanoma cell line A2058 [24]. It is mainly expressed in human brain, placenta, ovary and small intestine, and is undetectable in lymphoid tissues [39]. In rat and mouse, NPP2 is expressed on ciliary, choroid plexus and iris pigment epithelial cells, cartilage and cranial bone $[9,40,41]$. In the rat, expression of NPP $2 \alpha$ (p421.HB) has been correlated with intermediate stages of oligodendrocyte differentiation and early events in the formation of the myelin sheet [40]. To date, two splice variants NPP $2 \beta$ and NPP $2 \gamma$ have been identified. NPP $2 \beta$ was identified in human teratocarcinoma and retina, and lacks a highly basic 52amino-acid region located in the central domain $[39,42]$. Rat brain NPP2 $\gamma$ (PD-I $\alpha$ ), expressed in glial cells of the cerebellum, differs from NPP $2 \beta$ by the presence of 25 additional residues in the $\mathrm{C}$-terminal region of the protein [9].

NPP3 (gp130 $0^{\mathrm{RB} 13-6}$ ) was initially recognized by the monoclonal antibody RB13-6 as a $130-\mathrm{kD}$ glycoprotein on a specific subset of rat brain glial precursor cells with an intermediate expression of glial fibrillary acidic protein $[10,30]$. Expression of NPP3 is not observed in mature astrocytes, indicating that its expression is dependent on the stage of differentiation. NPP3 is also a marker of activated basophils and is identical to the activation molecule detected by monoclonal antibody 97A6 [43,44]. Activation of basophils by cross-linking $\mathrm{IgE}$ bound to $\mathrm{Fc}_{\varepsilon}$ receptors results in a dose-dependent up-regulation of NPP3. NPP3 has also been identified on human prostate [37], rat intestine, and the apical hepatocyte membrane [5]. It is also expressed on uterus, colon, basophils, mast cells and their progenitors, and on $\mathrm{PC} 12$, a tumor cell line resembling sympathetic neurons [37,43-45]. Although NPP3 is not expressed in liver, pancreas, and small intestine in human, it is detected in these tissues in rat $[5,12,37]$.

The human genes enpp1 and enpp2 (encoding NPP1 and NPP2) have been mapped to chromosome 6q22-23 and 8q24.1, respectively $[35,46,47]$. Human enpp 3 has been mapped in the vicinity of enppl on chromosome 6q22 [37]. The corresponding mouse genes of enpp1 and enpp 2 were assigned to chromosome $10 \mathrm{~A} 2$ and $15 \mathrm{D} 2$, respectively $[48,49]$. Screening of the mouse genome database (www.ncbi.nlm.nih.gov) with the EST-based mouse NPP3 sequence (Fig. 1) located the gene on chromosome 10A2. Screening of the rat genome database located rat enppl and enpp 2 on $1 \mathrm{p} 12$ and $7 \mathrm{q} 31$. Rat enpp 3 has been assigned to chromosome $1 \mathrm{p} 12$ [50]. The genomic location of enpp3 in the vicinity of enppl in human, mouse, and rat suggested that they originated by duplication of an ancestor gene.

Database searches located the genes of enpp 4 and enpp5, encoding NPP4 and NPP5, at 6p12.3 and 6p21.1-p11.2 on

Table 2

Extracellular molecules that affect the expression of E-NPPs

\begin{tabular}{llll}
\hline NPP & Effector & Cell type & References \\
\hline NPP1 & TGF- $\beta \uparrow$, IL-1 $\beta \downarrow$, IL-4 $\downarrow$ & Synoviocytes, & {$[58]$} \\
& TGF- $\beta \uparrow$, IL-1 $\downarrow \downarrow$, IGF-I $\downarrow$ & Chondrocytes, & {$[36,51,201]$} \\
& TGF- $\beta \uparrow$ & Hepatocytes & {$[199]$} \\
& Glucocorticoid hormones $\uparrow$ & Plasmacytoma & {$[8]$} \\
& $1,25-$ dihydroxyvitamin $\mathrm{D}_{3} \uparrow$, & Osteoblasts & {$[71]$} \\
& TGF- $\beta \uparrow$ & & \\
& aFGF $\uparrow$, bFGF $\uparrow$, IL-1 $\beta \downarrow$ & Osteosarcoma & {$[52]$} \\
NPP2 & IFN- $\gamma \downarrow$, IL-1 $\beta \downarrow$, IL-4 $\downarrow$ & Synoviocytes & {$[57,58]$} \\
& RA $\uparrow$ & Epithelial cells, & {$[61,62]$} \\
& BMP2 $\uparrow$ & neuroblastoma & \\
& bFGF $\uparrow$ & Mesenchymal & {$[41]$} \\
& Angiotensin II $\downarrow$, PDGF $\downarrow$ & progenitor cells & \\
& & Endothelial and & {$[143]$} \\
NPP3 & Smooth muscle cells & \\
& TGF- $\beta$ no effect & muscle cells & {$[65]$} \\
\hline
\end{tabular}

Compilation of data on the regulation of NPP expression in specific cell types. An upward and a downward arrow indicate increased and decreased NPP expression respectively.

BMP: bone morphogenic protein; FGF: fibroblast growth factor; IFN: interferon; IGF: insulin-like growth factor; IL: interleukin; PDGF: plateletderived growth factor; RA: retinoic acid; TGF: transforming growth factor. 
the human, at $17 \mathrm{~B} 2$ and $17 \mathrm{C}$ on the mouse, and both at $9 \mathrm{q} 12$ on the rat genome, respectively.

\subsection{Regulation of expression}

Although E-NPPs have been intensively investigated in the past few years, little is known about the regulation of their expression. Expression appears to be constitutive in some cell types, e.g. plasma cells and chondrocytes, but inducible in others. Published data compiled in Table 2 indicate that the TGF- $\beta$ signalling pathway has an important function in NPP expression (Fig. 2) and demonstrate a growth factor-dependent but cell proliferation-independent increase in NPP expression. TGF- $\beta$ up-regulates the expression of NPP1 in chondrocytes and osteoblasts, but does not induce expression in osteosarcoma cells, in which an FGF-induced expression was demonstrated $[51,52]$. In chondrocytes the TGF- $\beta$ induction of NPP1, accompanied by an enhanced transport to the plasma membrane, is antagonized by interleukin-1 $\beta$ (IL-1 $\beta$ ) [36,51]. NFk-Bmediated induction of Smad7 or inhibition of the transcriptional activity of Smad3 by SAPK/JNK activated c-Jun or JunB has been reported to underlie the inhibition of TGF- $\beta$ signalling by IL-1 (Fig. 2) [53,54]. NPP1 is expressed constitutively at high levels by mouse plasmacytoma cells, but its expression can be increased by glucocorticoids [8]. Whether enhanced NPP1 expression is due to sequestration of proinflammatory transcription factors (AP-1, NFAT, NFk-B, STATs) by the glucorticoid-glucocorticoid receptor complex, and activation of TGF- $\beta$ signalling upon attenuation of inhibitory Smad expression (Fig. 2), remains to be determined.

The expression of NPP2 and NPP3 increases during osteogenic and chondrogenic differentiation induced by bone morphogenic protein-2 $[41,55]$. In fibroblast-like synoviocytes of patients with rheumatoid arthritis that express high levels of TGF- $\beta$ [56], NPP2 expression is strongly increased and is down-regulated by interferon- $\gamma$ (IFN- $\gamma$ ) and IL-1 $\beta$ [57,58]. These cytokines may down-regulate NPP2 expression by induction of the TGF- $\beta$ signalling inhibitors Smad6 and Smad7 (Fig. 2) [53,59]. Retinoic acid, an inducer of TFG- $\beta$ in neuroblastoma cell lines, increases the expression of NPP2 and potentiates the Wnt- 1 mediated expression of NPP2 in C57MG mouse mammary epithelial cells [60-62]. Furthermore, TGF- $\beta$ activates the SAPK/ JNK pathway via MKK4/MKK7 in a Smad-independent manner [63] and MKK7 has been shown to up-regulate the expression of NPP2 in human embryonic kidney cells [64].

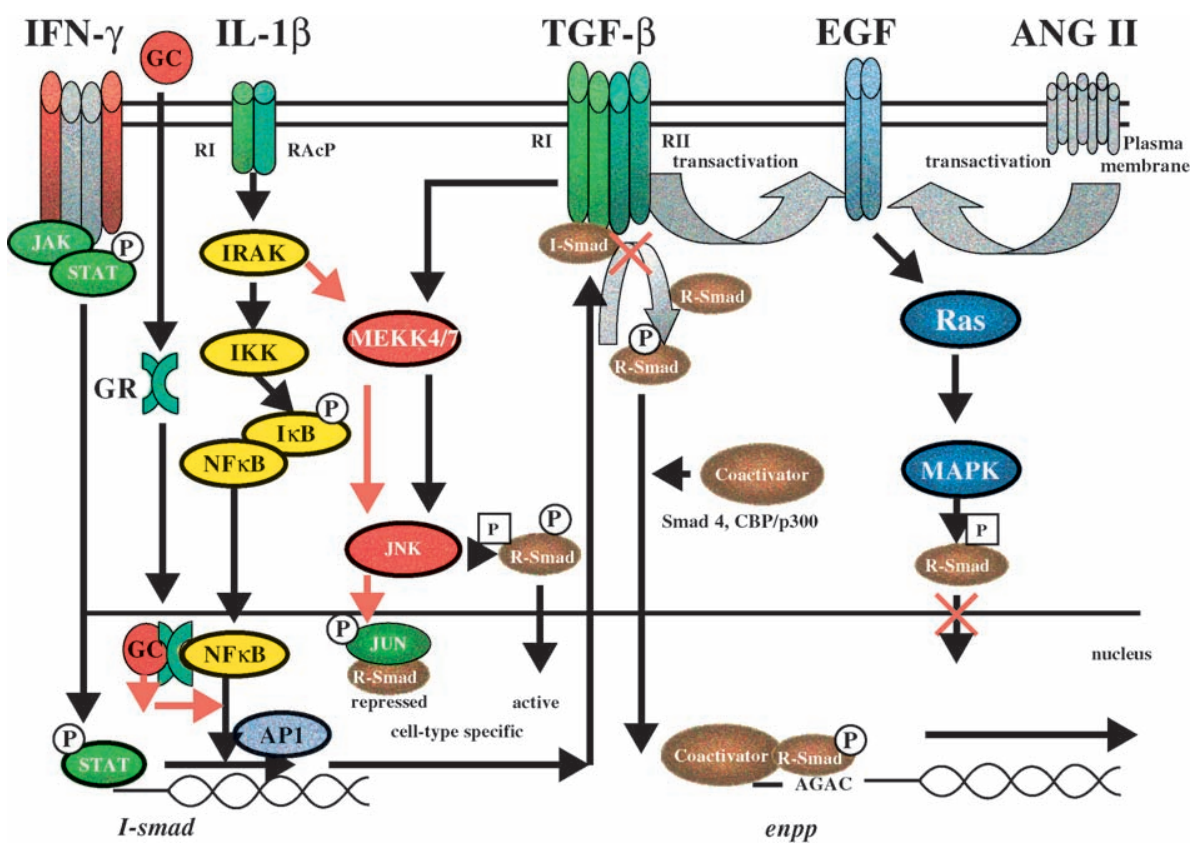

Fig. 2. Pathways that modulate the signal transduction of TGF- $\beta$ affect NPP expression. TGF- $\beta$ /activin and BMP receptor activation phosphorylates the Cterminal -SSXS- sequence ( $(\mathrm{P})$ of R-Smad 2, 3 and 1, 5, 8 respectively. Complete activation and nuclear translocation of phosphorylated Smads requires the CoSmad 4 or co-activator CBP/p300. The activated complex binds to the Smad-binding element (SBE, -AGAC-) of TGF- $\beta$ responsive genes. Putative SBEs are present in the promoter of hNPP1 (AB032016) at positions - 188, - 242, - 358, - 464 and -671 ; of hNPP2 (D45914) at positions - 79, - 531, - 1485 and -1745 ; and of hNPP3 (AF119714) at positions -60 and -65 . The nucleotide before the ATG start codon is taken as -1 . IFN- $\gamma$ and IL-1 $\beta$ antagonize TGF- $\beta$ signalling by a cell-specific induction of the inhibitory Smad 7 (I-Smad) mediated by activation of STAT and NF- $\kappa$ B, respectively. Glucocorticoid (GC)-glucocorticoid receptor (GR) complexes sequester NFkB that becomes inactive in gene transcription. I-Smad associates with the TGF- $\beta$ type I receptor and prevents the association of R-Smads. TGF- $\beta$ receptors also activate JNK by a Smad-independent feedback mechanism involving activation of the MAPK/ ERK kinase kinase (MEKK) 4/7. MEKK 4/7 is also activated by the IL-1 receptor-associated kinase (IRAK). Depending on the cell type, JNK activates cJun/ JunB that associates with Smad 3 into an inactive complex (red arrow) or JNK phosphorylates Smad 3 outside its -SSXS- motif [P], resulting in an enhanced activation and nuclear accumulation. TFG- $\beta$ and angiotensin II (ANG) receptors transactivate the EGF receptor by a metalloprotease-dependent mechanism resulting in MAPK/ERK activation. Phosphorylation of Smad 1, 2 and 3 by MAPK outsite its -SSXS- motif ([P]) inhibits its translocation to the nucleus. 
Angiotensin-II and platelet-derived growth factor (PDGF) decrease NPP3 expression in vascular smooth muscle cells (VSMC) [65]. Angiotensin, an inducer of PDGF-B expression in newborn rat VSMC, negatively regulates TGF- $\beta /$ Smad signalling by a Ras/ERK-dependent mechanism involving transactivation of the EGF-receptor (Fig. 2) $[66,67]$.

\section{Physiological and pathophysiological functions of $E$ - NPPS}

E-NPPs hydrolyze a broad range of substrates and influence many physiological processes. Dysfunction of ENPPs has been shown to be involved in the pathophysiology of several diseases, although it is often unclear whether changes in E-NPP expression are a cause or an effect of the disease.

\subsection{E-NPP regulates bone and cartilage mineralization}

\subsubsection{NPP1 controls mineralization}

A tight balance between pyrophosphate (PPi) and orthophosphate $(\mathrm{Pi})$ concentration governs physiological mineralization processes in bone, teeth, and growth plate cartilage $[68,69]$. PPi is required to induce calcification [70], the main extracellular source being hydrolytic degradation of nucleoside triphosphates by NPPs (Fig. 3). NPP1 has been correlated with matrix vesicle (MV) nucleotide pyrophosphatase activity and the generation of intravesicular and extracellular PPi (ePPi), and has been identified as the main ePPi-generating enzyme of osteoblasts and chondrocytes $[29,36,71]$. Matrix calcification by osteoblasts is mediated by release of PPi-enriched MVs. These vesicles contain proteins that sequester calcium and a cascade of hydrolytic enzymes including alkaline phosphatase, ATPase, and NPP1. These enzymes control the release of Pi and PPi from ATP as well as the conversion of PPi into Pi [72]. In extracellular fluids calcium and phosphate concentrations are close to the deposition point of basic calcium phosphate (BCP, hydroxyapatite).

PPi not only initiates but also regulates mineralization by suppressing hydroxyapatite crystal deposition from amorphous calcium phosphate, pointing to NPP1 as an important regulator of mineralization [73-75]. In addition, elevated levels of ePPi often result in pathological calcification characterized by the formation of calcium pyrophosphate dihydrate (CPPD) crystals. A distorted balance of Pi/PPi still allows crystal nucleation but ultimately leads to abnormal ossification, since PPi also functions as a physiological inhibitor of this process (Fig. 3).

Growth factors and interleukins that regulate the expression of NPP1 (Table 2, Fig. 2, and Section 2.3) determine the rate and extent of mineralization. A modest increase in NPP1 is sufficient to significantly increase ePPi [76].

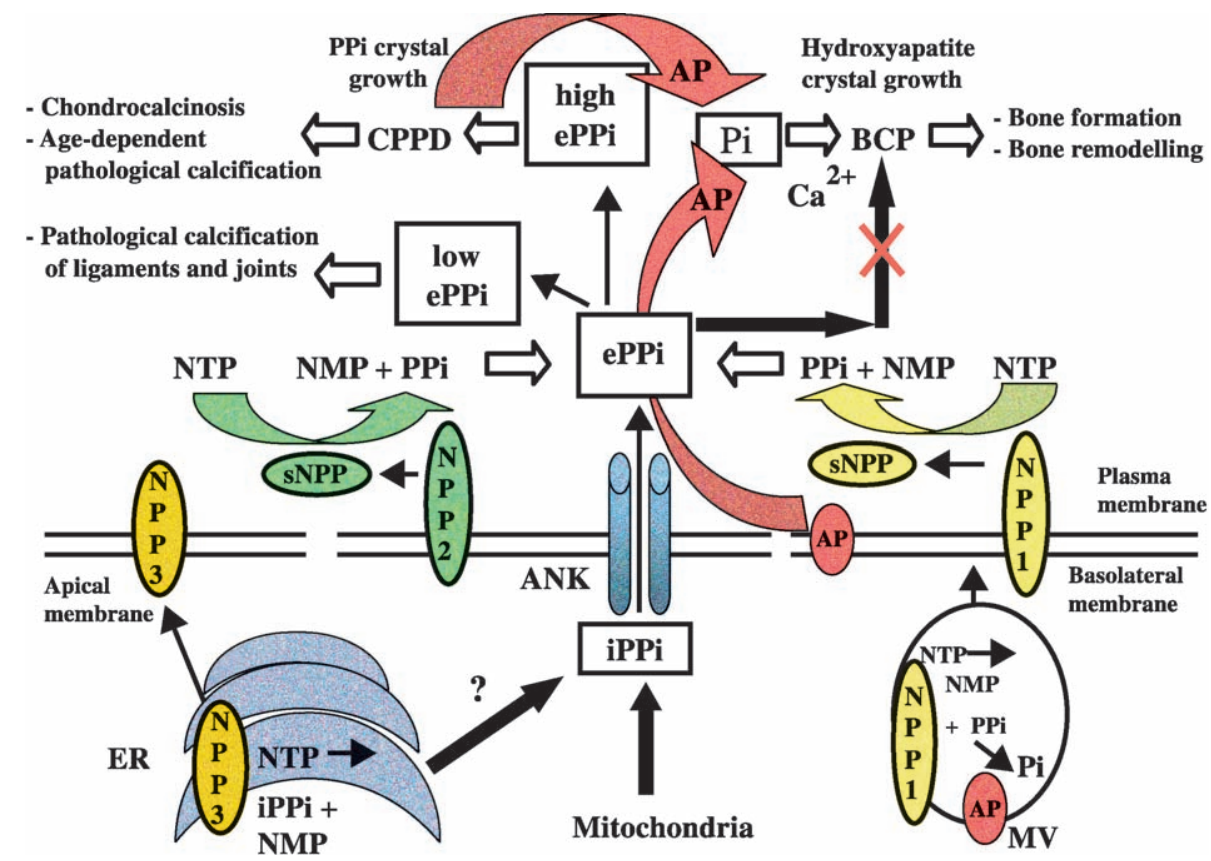

Fig. 3. Pyrophosphate in physiological and pathophysiological calcification processes. Intracellular pyrophosphate (iPPi) is generated in matrix vesicles (MV) by hydrolysis of NTP by NPP1 and in the lumen of the endoplasmic reticulum (ER) mainly by NPP3. Mitochondria have been reported to contribute to and regulate iPPi (for a review see Ref. [69]). ANK transports iPPi outside the cell. Extracellular PPi (ePPi) is mainly generated by membrane-bound and soluble NPP (sNPP) 1-2. In physiological conditions ePPi is hydrolyzed by alkaline phosphatase (AP) into Pi that, together with $\mathrm{Ca}^{2+}$, is integrated into basic calcium phosphate (BCP, hydroxyapatite) crystals. BCP crystal formation is controlled by ePPi. Excess ePPi results in pathological calcification characterized by calcium pyrophosphate dihydrate (CPPD) crystal formation. A low level of ePPi causes pathological calcification of ligaments and joints. 
In chondrocytes, NPP1 generates PPi in both the ER and Golgi during its transport to the plasma membrane. In contrast, NPP3 (B10), which is predominantly localized in the ER, mainly contributes to intracellular PPi (iPPi) (Fig. 3) [76-78]. Intracellular PPi is transported out of the cell by a probenecid-sensitive anion transport channel containing the transmembrane protein ANK [69]. Together with PPi generated by E-NPP, ANK determines the concentration of ePPi (Fig. 3; Section 3.1.4). Although NPP3 is present in articular cartilage, it is unable to compensate a loss of NPP1 activity, partly due to a different subcellular localization of NPP1 and NPP3 [76].

\subsubsection{Up-regulation of NPP1 is associated with chondro- calcinosis}

Since the pyrophosphate (PPi) and inorganic phosphate (Pi) concentration is critical for physiological mineralization, regulation of NPP1 expression must be tightly controlled. There is considerable body of experimental evidence that increased NPP1 levels may contribute to the development of pathological mineralization (reviewed in [79]). TGF- $\beta$, present in a latent form in cartilage, potently increases PPi generation as a result of an increased expression of NPP1 on chondrocytes $[51,80,81]$.

There is increasing evidence that PPi levels are regulated by opposing actions of NPP1, which generates PPi, and tissue-nonspecific alkaline phosphatase (TNAP), which degrades PPi into Pi [82]. Consistent with this idea, PPi levels are increased by TGF- $\beta$-induced up-regulation of NPP1 and down-regulation of alkaline phosphatase [51]. The TGF- $\beta$-mediated up-regulation, as well as the basal NPP1 level, is antagonized by the proinflammatory cytokine IL-1 $\beta$ [51]. The observed increase in IL-1 $\beta$ levels in patients with rheumatoid arthritis, as compared to patients with osteoarthritis and normal individuals, down-regulates NPP1 and may account for the decreased synovial PPi levels and the decreased bone calcification density in this disease $[81,83,84]$.

Pathological mineralization is often accompanied by crystal deposition in joints due to increased PPi formation. In idiopathic chondrocalcinosis or CPPD deposition disease, an elevated PPi concentration in joints can be partially accounted for by an increased NPP1 activity [85-88]. Crystal formation is further facilitated by the fact that the synovial fluid of these patients has an ATP concentration $(200 \mathrm{nM})$ that is twice that in normal joints [89]. Deposition of $\mathrm{BCP}$ crystals is frequently observed in this condition [88], but whereas BCP crystal deposition is correlated with joint degeneration, often in association with acute arthritis, CPPD crystal formation appears in an age-dependent manner [81].

\subsubsection{Deficiency of NPP1 is associated with pathological calcification of ligaments and joint capsules}

Since NPP1 is a major source of ePPi, and PPi is a potent inhibitor of hydroxyapatite formation, it seemed reasonable to expect that deficiency of NPP1 might result in pathological calcification. This has been shown to be the case in ttw (tiptoe walking) mice where the NPP1 gene is disrupted by a natural recessive mutation [90]. An essentially identical phenotype is seen in mice in which the NPP1 gene is disrupted by homologous recombination [91]. In each case, the mice show an increasing age-dependent calcification of ligaments, joint capsules, and tendons.

In view of the opposing and reciprocal actions of NPP1 and TNAP in the production and hydrolysis of ePPi, it is interesting to note that 'double knockout' mice in which both genes were deleted have a less severe phenotype than single knockouts where only the TNAP gene was deleted $[82,92]$.

The only reported case of NPP1 deficiency in humans was in a 2-year-old boy with iodopathic infantile arterial calcification, in which there was peri-arterial and periarticular calcification [93]. This child had very low NPP1 levels, and was heterozygous at the enpp1 locus, although the coding sequence was normal. The exact nature of the defect was not established.

A much more common human condition in which abnormalities of NPP1 expression have been suspected is ossification of the posterior longitudinal ligament of the spine (OPLL), which is a significant cause of myelopathy especially in Japan and Southeast Asia. The disease involves ectopic bone formation in the paraventral ligament and spinal-cord compression [94]. Genetic analysis of the NPP1 gene in OPLL reveals a significant association with a mutation in intron 20 [95]. Deletion of T, 11 nucleotides upstream from the splice acceptor site of intron 20, appears to render individuals more susceptible to abnormal ossification of the spinal ligaments [95].

There are a number of similarities between the ttw mice and human OPLL $[90,96,97]$. However, it cannot be assumed that the ttw mouse is an exact homologue of human OPLL. Unlike OPLL, the observed heterotypic ossification in ttw mice does not only occur in the spinal ligaments, but also in the joint capsules, tendons, tendon entheses, cartilage, and peripheral ligaments [90]. However, no convincing evidence for a changed NPP1 activity in OPLL has yet been reported, and the association with the variant sequence in intron 20 has not been shown to result in changed NPP1 activity.

\subsubsection{Extracellular PPi is determined by NPP1 and ANK}

From the foregoing, it would appear that the concentration of ePPi must be maintained within a very narrow range. Too little pyrophosphate causes the pathological deposition of hydroxyapatite, while too much causes the deposition of CPPD crystals (Fig. 3).

This point is reinforced by a second mutant strain of mice (ankylosing, or ank), in which a completely different gene is involved, but the phenotype is remarkably similar to that of ttw and NPP1-knockout mice. In each case, the mutations are associated with decreased ePPi. The mutation in ank 
mice resides in a gene that encodes a multipass transmembrane protein that appears to be a pyrophosphate transporter [98]. The mutation has been shown to involve loss of function, with increased iPPi and reduced pyrophosphate export, consistent with its recessive inheritance [98]. These results are consistent with the NPP1 mutants, in that reduced levels of ePPi promote the excessive deposition of hydroxyapatite.

These data are extended by recent studies of mutations in the human ank gene. Remarkably, mutations have been found involving loss and gain of function. Both result in pathological calcification, with deposition of hydroxyapatite and CPPD, respectively [99]. A French family was found to have a recessive mutation in the first transmembrane region that resulted in loss of function, elevated iPPi, and presumably reduced ePPi. Loss of ank function was accompanied by deposition of hydroxyapatite in and around joints, similar to the ank mouse.

In contrast, a British family was found to have a dominantly inherited mutation in the ank gene, resulting in addition of four amino acids at the $\mathrm{N}$ terminus. This mutation was accompanied by a gain of function, with a modest increase in the ability to export pyrophosphate. Several other "gain of function" mutants were also found. In each case, the "gain of function" mutants were accompanied by the deposition of CPPD characteristic of the common sporadic forms of human chondrocalcinosis [99]. These results seem consistent with the evidence that increased pyrophosphate generated as a result of NPP1 activity may play a causal role in the common forms of chondrocalcinosis [100].

The functional relationships, if any, between the ANK protein and NPP1 remain to be discovered. Loss of one allele of one gene is not sufficient to cause disease, but the loss of two alleles at either locus causes pathological deposition of hydroxyapatite. It would be interesting to examine the phenotype of mice that are heterozygous for both loci.

The striking similarities between under- and over-activity of NPP1 and ANK proteins suggest a functional relationship. Do they work sequentially or independently? Sequential action may explain some of the data but has several difficulties. Pyrophosphate would be generated by NPP1 in the interior of intracellular organelles, transported into the cytosol, and then transported out of the cytosol to the exterior of the cell via ANK (Fig. 3). Homozygous disruption of either gene would result in pathological deposition of hydroxyapatite. Although NPP1 must be present in the ER and Golgi on its way to the cell surface, the $\mathrm{pH}$ inside these organelles is mildly acidic and since the $\mathrm{pH}$ optimum for NPPs is rather alkaline, this would result in very low enzyme activity. At the present time, it seems more likely that these pathways are independent and operate in parallel, with an independent source of cytosolic $\mathrm{PPi}$, perhaps from exchange with ADP in mitochondria [69].
To summarize, it must be concluded that the ank and ttw mice confirm the importance of maintenance of a narrow range of ePPi to prevent pathological calcification, but the details of the way that these pathways interact with each other have yet to be elucidated.

\subsection{E-NPPS modulate nucleotide-mediated signal trans- duction}

\subsubsection{Modulation of purinergic receptor signalling}

Extracellular nucleotides, and in particular ATP and adenosine, elicit a broad range of responses in biological processes as diverse as neurotransmission, neuroprotection in hypoxia and ischemia, regulation of cardiovascular function, platelet aggregation, smooth muscle contraction, secretion of hormones, modulation of the immune response and control of cell proliferation, differentiation and apoptosis (Fig. 4) $[30,45,101-110]$.

In neurons, ATP is stored in synaptic vesicles in millimolar concentrations and is released into the synaptic cleft upon excitation. There is also a large and convincing body of evidence that ATP and UTP can be specifically released from non-neuronal cells by non-lytic transport-mediated mechanisms [111-114]. Both pre- and post-synaptic neuromodulation by ATP and its degradation product adenosine have been demonstrated, and are mediated by the activation of P2 and P1 purinergic receptors, respectively $[115,116]$. NPPs and other ecto-nucleotidases differentially expressed on specific cell types can hydrolyze ATP and generate adenosine, and thereby have the potential to terminate signalling by $\mathrm{P} 2$ receptors and activate signalling by $\mathrm{P} 1$ (Fig. 4).

Nucleotides have been shown to affect the proliferation of different cell types, although the results are not always unequivocal and the mechanisms may be complex and indirect, depending on the cell type and the presence of ecto-nucleotidases. ATP stimulates the proliferation of primary astrocytes and aortic smooth muscle cells but has no effect on the growth of transformed mouse fibroblasts [117119]. In contrast, several tumor cell lines are growthinhibited in response to ATP $[120,121]$. Adenosine inhibits or stimulates the proliferation of cells depending on its extracellular concentration and on the cell type $[108,122$, 123].

The different effects of ATP and adenosine may be understood as reflecting the final outcome of differential expression of purinergic receptor subtypes, together with the modulating effects of cell surface-bound nucleotidases which have the potential to generate active signalling ligands or terminate signalling by hydrolyzing them at the surface of specific cells $[30,45,107,108,124]$. These enzymes include members of the ecto ATPase, ectoapyrase, E-NPPs and ecto-nucleotidase families which hydrolyze ATP into ADP, AMP, and adenosine [124], resulting in the stimulation of distinct nucleotide receptor subtypes which are linked to the activation of ligand- 


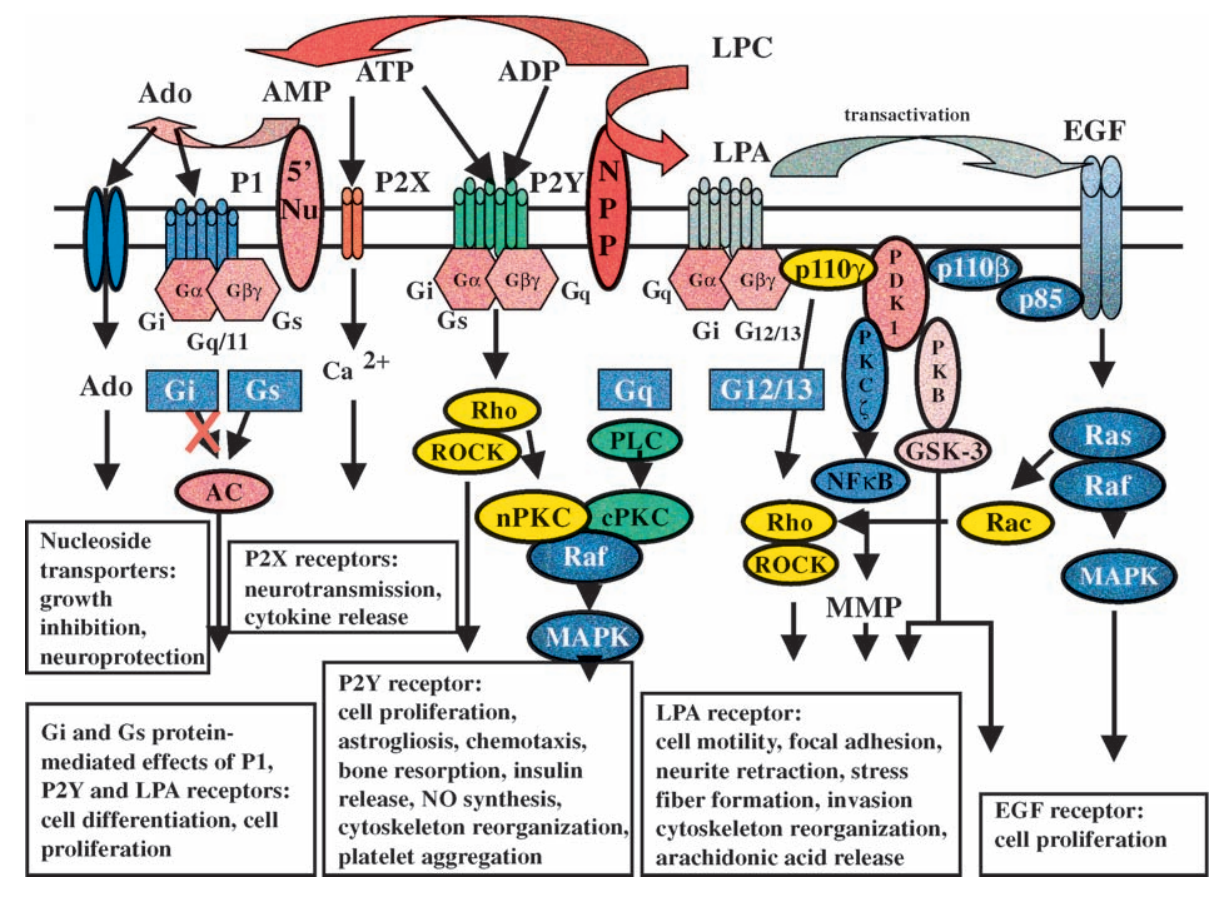

Fig. 4. Effect of NPP on purinergic and lysophosphatidic acid (LPA) receptor signalling. Depending on the cell type, purinergic and LPA receptors can activate Gi-, Gs-, Gq- and G12/13-coupled (blue boxes) signal transduction pathways. NPPs hydrolyze nucleotide di- and triphosphates into monophosphates and terminate $\mathrm{P} 2 \mathrm{X}$ and $\mathrm{P} 2 \mathrm{Y}$ receptor signalling coupled to $\mathrm{Ca}^{2+}$-influx and to $\mathrm{Gi}\left(\mathrm{P} 2 \mathrm{Y}_{12}, 13\right)$, Gs $\left(\mathrm{P} 2 \mathrm{Y}_{11}\right)$ and Gq $\left(\mathrm{P} 2 \mathrm{Y}_{1,2}, 4,6,11\right)$ proteins. P2Y receptors are coupled to RhoA and can activate MAPK by a RhoA- and novel PKC (nPKC)-dependent or a PLC- and conventional PKC (cPKC)-dependent pathway, and modulate $\mathrm{AC}$ by $\mathrm{Gi}$ and Gs proteins. AMP is hydrolyzed into adenosine (Ado) by 5 '-nucleotidase ( $5^{\prime}$-Nu). Ado activates $\mathrm{P} 1$ receptors that modulate AC by Gi (A1, A3) and Gs (A2) proteins, and activate PLC (A1, A3) by Gq/11. Ado is internalized by nucleoside transporters. NPP2 hydrolyzes lysophosphatidylcholine (LPC) into LPA resulting in stimulation of LPA receptors. These receptors can couple to Gi/o (Gi), G12/13 and Gq proteins resulting in the activation of several signalling pathways including Gi protein-mediated inhibition of adenylate cyclase (AC), Gq protein-mediated activation of MAPK involving phospholipase C (PLC) and conventional PKC (cPKC), G12/13 protein-mediated activation of PI 3-K $\gamma$ (p110 $\gamma$ ) and its downstream effectors RhoA and phosphatidylinositoldependent kinase (PDK)-1, or activate MAPK and PI 3-K $\beta$ (p110 $\beta$ ) by transactivation of the epidermal growth factor (EGF) receptor. The small GTPase RhoA is coupled to Rho-associated coiled-coil-containing protein kinase (ROCK) involved in the reorganization of the cytoskeleton. Downstream effectors of PI 3-K and PDK-1 are PKB and PKC $\zeta$. PKB regulates the cell cycle by phosphorylation of glycogen synthase kinase-3 (GSK-3). PKC $\zeta$ is involved in invasion by activation of $\mathrm{NF} \kappa \mathrm{B}$, a transcription factor of matrix metalloprotease (MMP) genes.

gated cation channels, phospholipase $\mathrm{C}$, or adenylate cyclase.

For example, modulation by NPP1 of the activation of the $\mathrm{P} 2 \mathrm{Y}_{12}$ receptor, negatively coupled to adenylate cyclase, has been demonstrated in rat C6 glioma cells $[38,125,126]$. Modulation of the action of ATP on these cells by NPP1 seems to involve several different mechanisms. Both ATP and adenosine inhibit the growth of $\mathrm{C} 6$ cells. However, if the enzymatic activity of NPP1 is inhibited, ATP becomes a growth stimulator of these cells, suggesting that hydrolysis of ATP into AMP and subsequently into adenosine by 5'nucleotidase is responsible for the observed ATP-mediated growth inhibition [121]. Inhibition of cell growth by ATP might be an indirect effect explained by cellular uptake of adenosine by specific transporters and induction of pyrimidine starvation $[127,128]$. The data might also be explained on the basis that inhibition of hydrolysis of extracellular ATP by blocking NPP1 would shift the balance towards P2 receptor activation and prevent $\mathrm{P} 1$ receptor activation. A third possible mechanism could involve the modulation of the activity of growth factors and growth inhibitors by extracellular kinases which are directly coupled to the level of the $\gamma$-phosphate donors and may also affect cell growth [129, and references therein].

E-NPPs have also been proposed to play a role in ATPinduced apoptosis [130]. ATP-mediated apoptosis may result from either activation of the $\mathrm{P} 2 \mathrm{X}_{7}$ receptor as shown for mast cells, platelets, macrophages, and lymphocytes [109], or generation of adenosine and activation of the A3 (P1 purinergic) receptor as shown for astrocytes, neuroblastoma, and mesangial cells $[110,131]$. Pyridoxalphosphate-6-azophenyl-2', 4'-disulfonic acid, a potent inhibitor of NPP1 [125], has been shown to abolish ATP-induced apoptosis in the mouse neuroblastoma cell line N1E-115 by inhibition of the hydrolysis of ATP into adenosine [110]. The neuroprotective effect of adenosine in hypoxia/ischemia may also be due to inhibition of neurotransmitter release by activated A1-receptors [104,132]. In this case, as previously, adenosine could be derived from ATP by the action of ectonucleotidases.

\subsubsection{Nucleotide recycling}

Proliferating cells have a large requirement for purine and pyrimidine nucleotides, which may be generated de 
novo or recycled from extracellular nucleotides through a salvage pathway. E-NPPs are proposed to be part of a hydrolytic cascade system that culminates in the conversion by $5^{\prime}$-nucleotidase of nucleoside monophosphates into nucleosides that are then internalized by cells through specific nucleoside transporters [133]. A function for ENPPs in this salvage pathway has been demonstrated in T-lymphocytes, hepatocytes, and the intestine when de novo synthesis is inhibited by azaserine [32]. T-lymphocyte proliferation is dependent on the presence of extracellular $\mathrm{NAD}^{+}$, ADP-ribose, or AMP. Degradation of extracellular $\mathrm{NAD}^{+}$proceeds through the concerted action of $\mathrm{CD} 38$, which is an ecto-NAD ${ }^{+}$-glycohydrolase, and NPP1 [32]. CD38 generates ADP-ribose, which is subsequently hydrolyzed into AMP by NPP1. Ecto-5'-nucleotidase finally degrades AMP into adenosine, which is taken up by cells. Treatment of T-lymphocytes with membrane-permeable activators of PKA or PKC results in a coordinated upregulation of CD38 and NPP1 expression, suggesting a functional hydrolysis cascade on activated T-lymphocytes [32].

The liver secretes nucleotides into the bile as autocrine and paracrine regulators of bile secretion [133-135]. NPP3, expressed on the apical surface of hepatocytes, is proposed to function in the recycling of nucleotides from bile in rodents $[5,26,133]$. This mechanism would appear unlikely in humans, since NPP3 is not expressed in human liver $[12,37]$ In addition, it has been suggested that NPP3 plays a role in the intestinal uptake of nutritional nucleotides by enterocytes $[5,136]$.

\subsection{Motility and invasion of tumor cells}

NPP2 was originally identified in the conditioned medium of the A2058 melanoma cell line as a factor that promoted cell motility and given the name 'autotaxin' [24]. It has subsequently been detected in many tumors including hepatocellular carcinoma [137], neuroblastoma [138], prostate carcinoma [139], and non-small-cell lung cancer [140]. NPP2 has been shown to augment the invasive and metastatic potential of ras-transformed NIH3T3 cells. Furthermore, it stimulates blood vessel formation in tumors arising from these cells as well as in human endothelial cells, indicating that NPP2 has angiogenic properties $[142,143]$. In this context, it is interesting to note that IL-4, a cytokine reported to inhibit angiogenesis [144-146], down-regulates NPP2 expression [58].

NPP2 stimulates both random and directed tumor cell migration at picomolar concentrations [24], which would only seem possible for a molecule with enzymatic properties. An important role has been attributed to the catalytic site of NPP2 since mutation of $\mathrm{Thr}^{210}$ into Ala or Asp abolished its ability to stimulate cell motility. It has been proposed that dephosphorylated NPP2 actively promotes this motility [141]. Until recently, however, it was impossible to make a functional linkage between the NPP2 activity and stimulation of cell motility because there was little evidence that this effect was mediated by nucleotides. An exciting breakthrough in the elucidation of the NPP2 promoted motility came from the discovery that NPP2 has intrinsic lysophospholipase D (PLD) activity that results in the generation of LPA from plasma lysophosphatidylcholine $[2,3]$. LPA is known to stimulate cell motility and invasion by signalling pathways that activate Rho GTPases (Fig. 5) [147].

The physiological activities of LPA are mediated by three receptors of the endothelial differentiation gene family, e.g. Edg2 (LPA1), Edg4 (LPA2) and Edg7 (LPA3), that can activate $G_{\mathrm{q}}, G_{i}$, and $G_{12 / 13}$ subfamilies of $G$ proteins. $G_{i}$ is pertussis toxin-sensitive and is coupled to Ras and MAPK by $\mathrm{G}_{\beta \gamma}$ transactivation of the $\mathrm{p} 110 \beta$ PI 3-K subunit recruited to the EGF receptor (Fig. 4) [148]. This transactivation is also required for the initiation of protein synthesis stimulated by LPA-activated receptors [67]. In human melanoma cells NPP2 has been shown to promote motility by a G protein-coupled mechanism involving activation of the catalytic p110 $\gamma$ subunit of class $I_{B}$ PI 3-K [149]. The discovery of lysophospholipase activity of NPP2 now allows this observation to be integrated into the known signalling pathway by which phosphatidic acid acts.

This activity of NPP2 was all the more surprising because of the lack of structural similarity between this substrate and nucleotides (Fig. 5), which had been considered the most likely physiological substrates 'in vivo'. In view of the high degree of conservation of the amino sequences surrounding the active site threonine of NPPs, the question arises whether other members of the NPP family also have PLD activity. This issue is currently being intensively studied.

There is some indirect evidence that this may be the case for NPP3, which has been shown to have invasion-promoting properties. In prenatal and neonatal rats, NPP3 is expressed on a specific subset of glial cells which are highly susceptible to malignant transformation by $N, N^{\prime}$-ethylnitrosourea $[10,30]$. A role of NPP3 in development and tumoral transformation was demonstrated by showing that its expression in fibroblasts and glioma cells induced morphological changes, synthesis of differentiation specific proteins, and enhanced invasive properties [150]. NPP1 is the only E-NPP present on invasive rat C6 glioma cells $[38,107,150]$ but its effect on motility and invasion remains to be determined.

NPP3 has also been suggested to be an early marker of cholangiocarcinoma, an adenocarcinoma derived from biliary cells. Its serum level increases significantly at the onset of the disease. The slightly smaller $(125 \mathrm{kD})$ soluble serum form of NPP3 has been proposed to be generated by proteolytic cleavage from the transmembrane form, but the exact mechanism remains to be elucidated [26]. NPP3 is expressed on the apical membrane of normal biliary cells in rodents, and proteolytic cleavage results in secretion into the bile [5]. However, a redistribution of NPP3 from the apical 


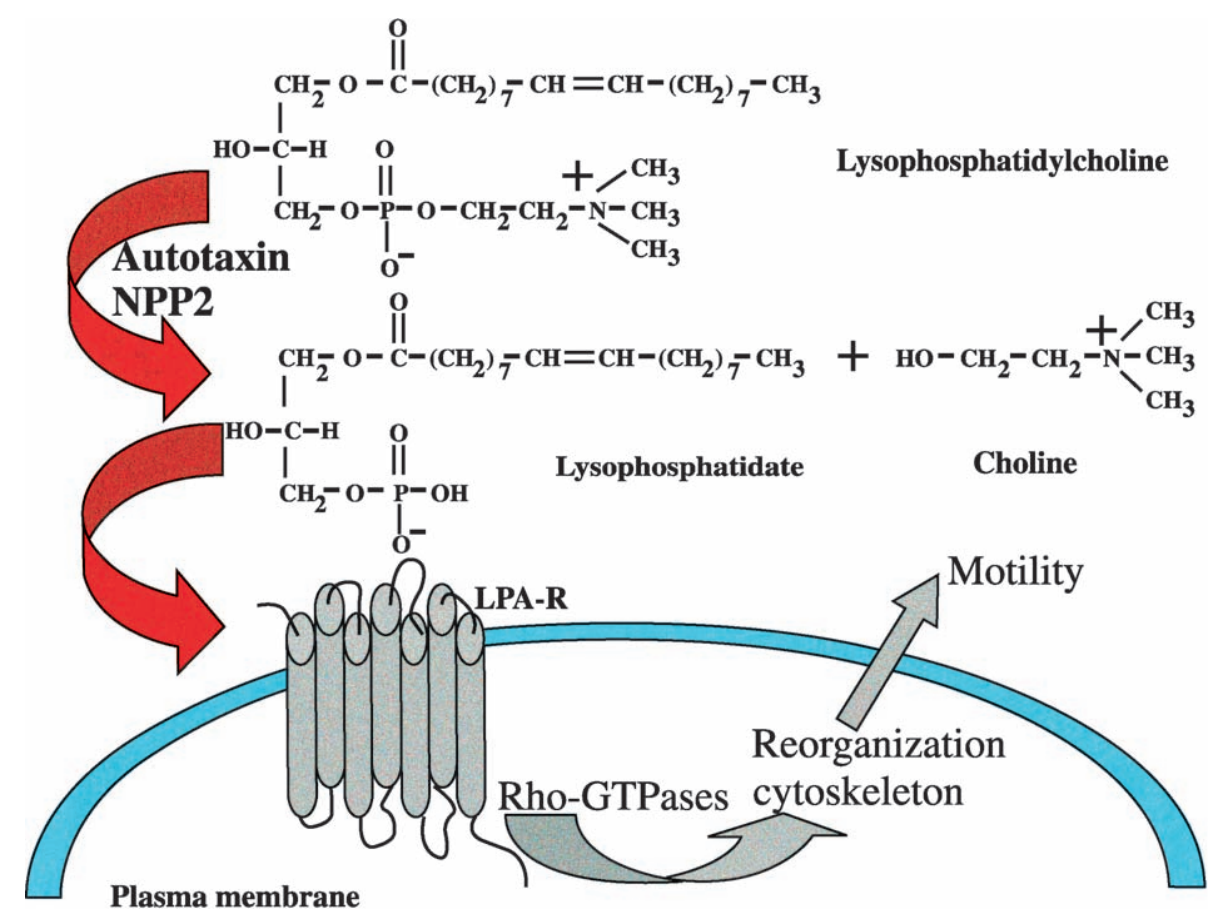

Fig. 5. Activation of lysophosphatidate (LPA) receptors by autotaxin (NPP2). NPP2 hydrolyzes lysophosphatidylcholine (LPC) into LPA and choline. Stimulation of LPA receptors (LPA-R) activates small GTPases of the RhoA family (Cdc42, Rac, Rho) by PI 3-K-dependent mechanisms (see Fig. 4). These GTPases are able to interact with and activate different downstream effectors [202] involved in motility-related processes, e.g. formation of membrane ruffles/ lamellipodia, filopodia, actin stress fibers and focal adhesion.

to the basolateral membrane in pathological conditions allows hydrolyzed NPP3 to be secreted into the blood stream $[151,152]$.

NPP3 is initially transported towards the basolateral surface. Subsequently, it is rapidly redirected towards the apical membrane by transcytosis [153]. Alterations in transcytosis in pathological conditions may lead to an abnormal basolateral sequestering of NPP3, but the precise mechanism of such redistribution is currently unclear. Although glycosylation has an important function in the correct transport of proteins to the cell surface, the glycans of NPP3 do not appear to contain an apical targeting signal [22], and glycosylation is not essential for transport of NPP3 to the cell surface or for secretion.

\subsection{Overexpression of NPP1 in diabetes mellitus: a controversial issue}

Non-insulin-dependent diabetes mellitus (NIDDM) is a very common and increasingly prevalent syndrome characterized by resistance to both endogenous and exogenous insulin. In NIDDM mutations in the IR gene are extremely uncommon [154,155], and the common forms of insulin resistance are due to a poorly understood post-receptor defect in the insulin-mediated signal transduction $[156,157]$. Insulin resistance may precede the onset of overt clinical disease by many years, and is correlated with an impaired IR kinase activity, although the IR gene is completely normal $[156,158,159]$. The presence of an inhibitor of IR tyrosine kinase activity in skin fibroblasts of patients with insulin resistance was suggested by Maddux et al. [160]. They purified a candidate inhibitor from dermal fibroblasts derived from a NIDDM patient, and the inhibitor was identified by partial amino acid sequencing as NPP1 [161]. The NPP1 protein level and enzymatic activity were increased in NIDDM patients.

These results have been somewhat controversial and there are a considerable number of studies in which no evidence is found for a role of E-NPP in diabetes. It is not clear whether the differing results reflect heterogeneity in patient subgroups or possibly methodological and technical issues. A subgroup of patients with pseudo-acromegalic insulin resistance showed no correlation between NPP1 overexpression and defective insulin action [162]. In vitro studies showed that overexpression of NPP1 in MCF-7 cells rendered them less sensitive to insulin, and overexpression in MDA-MB231 breast cancer cells was also associated with inhibition of IR tyrosine kinase activity [163]. Although elevated plasma levels of TGF- $\beta 1$ detected in NIDDM patients [164] may be responsible for the increased expression of NPP1, the regulation of NPP1 expression and its correlation with insulin resistance in different diabetic subgroups remains to be determined.

Many studies have shown a correlation between increased NPP1 expression and insulin resistance, but most have not addressed the question of causality. Insulin resistance is observed in up to $25 \%$ of the healthy non-diabetic non-obese individuals, and this population is at risk of 
developing diabetes if insulin resistance increases and/or insulin secretion declines [165]. In these individuals, an increased NPP1 protein content in adipose tissue and skeletal muscle has been correlated with a reduction in insulin sensitivity and IR tyrosine kinase activity [166168]. The NPP1 content was found to be inversely correlated with the insulin-stimulated glucose transport in skeletal muscle [169]. An inverse correlation between NPP1 levels and IR tyrosine phosphorylation has also been observed in muscle biopsies of obese insulin resistant rhesus monkeys [170]. Furthermore, an increased NPP1 content has been measured in rectus abdominus muscle biopsies and adipocytes of pregnant females developing gestational diabetes mellitus (GDM) and has been proposed to contribute to this disease, indicating a higher risk for type 2 diabetes with age $[171,172]$.

Clinical treatment of type 2 diabetes with the antihyperglycemic drugs pentoxifylline and metformin restores insulin sensitivity and decreases NPP1 expression [58,173]. Merck L7, a direct IR agonist, and Teliks TLK6998, an IR sensitizer, which belong to a new class of anti-diabetic agents, improve IR autophosphorylation in cells overexpressing NPP1 [174].

An alternative approach to establish a possible causal link between NPP1 and insulin resistance comes from human genotyping studies. A K121Q polymorphism has been identified in exon 4. Individuals with the Q allele showed higher glucose levels and increased insulin resistance [175]. However, this polymorphism is detected in Sicilian, Finish, and Swedish Caucasians but is absent in Danish Caucasians [175-177], so even if this association is causal, additional unidentified genes must contribute to the clinical phenotype.

The Q-allele of this polymorphism has also been linked to a faster progression of albuminuria and nephropathy in Italian type 1 diabetes patients [178] but was not correlated with microvascular complications in Danish type 1 diabetics [179]. In contrast, a study with 295 patients was unable to correlate the K121Q amino acid variant with the progression of diabetic nephropathy [180], while a study with 659 patients concluded that carriers of the Q variant of NPP1 have an increased risk of developing end-stage renal disease early in the course of type 1 diabetes [181]. So far, no data are available concerning whether the K121Q polymorphism alters NPP1 enzymic activity.

A cluster of three single nucleotide polymorphisms (G2897A, G2906C, and C2948T) in the $3^{\prime}$-untranslated region of the enppl gene has been shown to increase NPP1 mRNA stability and has been correlated with an increased NPP1 protein content and with insulin resistance [182]. In a multipoint linkage study, enppl was also identified as a positional candidate gene for insulin resistance near the chromosomal marker D6S403 [183].

What possible mechanisms could be involved in NPP-1mediated insulin resistance? Early cell-free studies showing inhibition of IR phosphorylation by NPP1 have been shown to be artifacts due to hydrolysis of ATP by NPP1 [184]. In vivo studies do not have this problem $[185,186]$. Evidence has also been presented that the mechanism is independent of the enzymatic activity of NPP1; inhibition of IR autophosphorylation by NPP1 has been demonstrated to occur even if NPP1 is inactivated by site-directed mutagenesis [187]. Although adenosine produced from ATP or ADP after successive hydrolysis by NPP1 and $5^{\prime}$-nucleotidase can modulate insulin signalling through the activation of P1receptors [188,189], pharmacological data suggests no role for adenosine in the pathogenesis of NIDDM [187].

More recently, immunoprecipitation experiments have suggested that NPP1-mediated inhibition of IR function is due to high affinity binding of NPP1 to the IR, as evidenced by the ability of the complex to withstand repeated washing. The observed inhibition was independent of NPP1 activity [190]. No physical association of NPP1 with the closely related IGF-I receptor was detected, suggesting that the interaction between NPP1 and the IR is highly specific. Therefore, it is surprising that NPP1 is not routinely encountered upon purification of the IR.

Correlation of the K121Q polymorphism with a higher risk for insulin resistance has been explained by a stronger interaction of NPP1 with IR in individuals with the Q allele [191]. This mutation is located in the first somatomedin Blike extracellular domain of NPP1, suggesting an extracellular interaction with IR. Deletion of the connecting domain/ fibronectin-like III domain (amino acids 485-599) of the IR $\alpha$ extracellular subunit abolished its association with NPP1, indicating that this domain is involved in the interaction $[190,192]$.

It should be emphasized that the reports on the involvement of NPP1 in insulin resistance are not universally accepted, and there is evidence to the contrary. Whitehead et al. [162] demonstrated that patients with genetic lesions in IR or insulin receptor substrate (IRS)-1 have a significant reduction in NPP1 expression rather than the increase seen in studies by other authors. Induction of diabetes in rats by high fat feeding did not alter NPP1 expression, and overexpression of the $\mathrm{N}$-terminal 257 amino acid residues of rat NPP1 did not change IR autophosphorylation, PI 3-K activation, or glucose uptake in highly insulin-sensitive 3T3-L1 adipocytes [193]. In Fisher rats relatively resistant to obesity, insulin resistance in muscle tissue is not associated with a change in NPP1 level [186]. Another study showed that overexpression of NPP1 in CHO cells did not impair IR autophosphorylation, downstream signalling to MAP kinase through Ras or IRS-dependent PI 3-K activation, but blocked the insulin-dependent activation of p70 S6 kinase [194].

IRS proteins have been shown to be involved in the 'in vivo' insulin effects on carbohydrate and lipid metabolism [195]. IRS-1 has a role in muscle and adipose tissue, while IRS-2 has a major effect in liver and muscle. Defects in IR signalling via IRS-2, involved in peripheral insulin actions and in pancreatic $\beta$-cell functioning, contribute to insulin 
resistance. Mice lacking the irs-2 gene develop progressive diabetes [196]. Hepatic insulin resistance is involved in this process, and failure of a $\beta$-cell compensation results in diabetes. It would be of interest to examine NPP1 expression in mice lacking the irs-2 gene.

In summary, evidence for a role of NPP1 in insulin resistance is inconsistent and contradictory, for reasons that are currently unclear. In view of the medical importance of type II diabetes, there is an urgent need for further studies that are capable of providing definitive answers.

\section{Conclusions}

Extracellular nucleotide hydrolysis has long been considered to serve a role in cellular nutrition by the removal and recycling of nucleotides from the extracellular medium. Recent work reveals a far more complex picture. During the past decade it has become clear that nucleotides are mediators of intercellular signalling. They control multiple physiological processes initiated by activation of specific cell surface receptors and their intracellular signal transduction pathways. Ectonucleotidases initiate, terminate, or modulate these signalling cascades.

It is now clear that specific ecto-nucleotidases expressed by cells stringently regulate the ecto-nucleotide metabolism in their microenvironment. Although E-NPPs mainly seem to be functional in physiological processes that require a balanced nucleotide hydrolysis, competition among the different substrates for binding in their catalytic site may be an additional factor that controls the processes affected by E-NPPs.

Depending on the cell type, E-NPPs initiate the hydrolysis of nucleotide tri- and diphosphates affecting a broad array of processes including bone and cartilage mineralization, recycling of nucleotides, cell motility, and diverse purinergic receptor-dependent mechanisms. The ability of E-NPPs to generate PPi has been shown to have profound effects on the calcification of cartilage, bone, ligaments, and joint capsules. Whether effects on purinergic signalling contribute to these effects is not yet clear.

The substrate specificity of the E-NPP family is not restricted to nucleotides. Besides phosphodiester bonds, phosphonate esters, and sulfate-phosphate bonds, phospholipids have recently been identified as substrates of NPP2, extending the function of this NPP to regulation of some receptors of the endothelial differentiation gene family, and hence to the control of cell motility.

Aberrant expression of E-NPP-family members has been observed in a number of disease states. However, the physiological mechanisms of E-NPP action are still unclear. In particular we know little concerning their physiological substrates 'in vivo'. The mechanisms and the signal transduction cascades resulting in an aberrant E-NPP expression are poorly documented. There is a need for more studies that examine causal links rather than mere correlations, but proving causality is difficult.

Research should also focus on the expression pattern of E-NPPs in specific cell types, the identification of the physiological substrates, elucidation of the signal transduction cascades that regulate their expression, and on the mechanisms that are affected by changes in expression. Progress would be greatly accelerated by the availability of a panel of monoclonal antibodies specific for each E-NPP protein. A similar panel of antibodies specific for each type of purinergic receptor would allow detailed histological studies using double labeling of single cells. This would probably result in the clarification of much uncertainty.

The recent exciting discovery of lysophospholipase activity for NPP2 raises many important questions. Is this activity also associated with other E-NPP family members? Is there aberrant expression of these enzymes in tumor cells? Does this influence their tendency to invade or metastasize? In the long term, answers to these questions may lead to novel drugs and treatments of diseases in which E-NPPs are involved.

\section{Acknowledgements}

This work is supported by BOF-NOI of the University of Antwerp (H.S.), the Fund for Scientific Research Flanders (H.S.), the "Emmanuel van der Schueren" foundation (B.G.), and the National Health and Research Council of Australia (J.W.G).

\section{References}

[1] M. Bollen, R. Gijsbers, H. Ceulemans, W. Stalmans, C. Stefan, Nucleotide pyrophosphatases/phosphodiesterases on the move, Crit. Rev. Biochem. Mol. Biol. 35 (2000) 393-432.

[2] A. Tokumura, E. Majima, Y. Kariya, K. Tominaga, K. Kogure, K. Yasuda, K. Fukuzawa, Identification of human plasma lysophospholipase D, a lysophosphatidic acid-producing enzyme, as autotaxin, a multifunctional phosphodiesterase, J. Biol. Chem. 277 (2002) 39436-39442.

[3] M. Umezu-Goto, Y. Kishi, A. Taira, K. Hama, N. Dohmae, K. Takio, T. Yamori, G.B. Mills, K. Inoue, J. Aoki, H. Arai, Autotaxin has lysophospholipase D activity leading to tumor cell growth and motility by lysophosphatidic acid production, J. Cell Biol. 158 (2002) 227-233.

[4] I. Banakh, A. Sali, V. Dubljevic, B. Grobben, H. Slegers, J.W. Goding, Structural basis of allotypes of ecto-nucleotide pyrophosphatase/ phosphodiesterase (plasma cell membrane glycoprotein PC-1) in the mouse and rat, and analysis of allele-specific xenogeneic antibodies, Eur. J. Immunogenet. 29 (2002) 307-313.

[5] L.J. Scott, D. Delautier, N.R. Meerson, G. Trugnan, J.W. Goding, M. Maurice, Biochemical and molecular identification of distinct forms of alkaline phosphodiesterase I expressed on the apical and basolateral plasma membrane surfaces of rat hepatocytes, Hepatology 25 (1997) 995-1002

[6] V. Bello, J.W. Goding, V. Greengrass, A. Sali, V. Dubljevic, C. Lenoir, G. Trugnan, M. Maurice, Characterization of a di-leucinebased signal in the cytoplasmic tail of the nucleotide-pyrophosphatase NPP1 that mediates basolateral targeting but not endocytosis, Mol. Biol. Cell 12 (2001) 3004-3015. 
[7] Y.I. Kamikubo, Y. Okumura, D.J. Loskutoff, Identification of the disulfide bonds in the recombinant somatomedin B domain of human vitronectin, J. Biol. Chem. 277 (2000) 27109-27119.

[8] N.F. Rebbe, S. Hickman, Modulation of nucleotide pyrophosphatase in plasmacytoma cells, Biochem. Biophys. Res. Commun. 175 (1991) 637-644.

[9] M. Narita, J. Goji, H. Nakamura, K. Sano, Molecular cloning, expression, and localization of a brain-specific phosphodiesterase I/ nucleotide pyrophosphatase (PD-I $\alpha$ ) from rat brain, J. Biol. Chem. 269 (1994) 28235-28242.

[10] H. Deissler, F. Lottspeich, M.F. Rajewsky, Affinity purification and cDNA cloning of rat neural differentiation and tumor cell surface antigen gp130 $0^{\mathrm{RB} 13-6}$ reveals relationship to human and murine PC-1, J. Biol. Chem. 270 (1995) 9849-9855.

[11] R. Gijsbers, H. Ceulemans, W. Stalmans, M. Bollen, Structural and catalytic similarities between nucleotide pyrophosphatase/phosphodiesterase and alkaline phosphatases, J. Biol. Chem. 276 (2001) $1361-1368$.

[12] K. Andoh, J.H. Piao, K. Terashima, H. Nakamura, K. Sano, Genomic structure and promoter analysis of the ecto-phosphodiesterase I gene (PDNP3) expressed in glial cells, Biochim. Biophys. Acta 1446 (1999) 213-224.

[13] J. Lee, I.D. Jung, S.W. Nam, T. Clair, E.M. Jeong, S.Y. Hong, J.W. Han, H.W. Lee, M.L. Stracke, H.Y. Lee, Enzymatic activation of autotaxin by divalent cations without EF-hand loop region involvement, Biochem. Pharmacol. 62 (2001) 219-224.

[14] M. Uriarte, W. Stalmans, S. Hickman, M. Bollen, Phosphorylation and nucleotide-dependent dephosphorylation of hepatic polypeptides related to the plasma membrane differentiation antigen PC-1, Biochem. J. 293 (1993) 93-100.

[15] C. Stefan, W. Stalmans, M. Bollen, Threonine autophosphorylation and nucleotidylation of the hepatic membrane protein PC-1, Eur. J. Biochem. 241 (1996) 338-342.

[16] N. Hosoda, S. Hoshino, Y. Kanda, T. Katada, Inhibition of phosphodiesterase/pyrophosphatase activity of PC-1 by its association with glycosaminoglycans, Eur. J. Biochem. 265 (1999) 763-770.

[17] Y. Oda, M.D. Kuo, S.S. Huang, J.S. Huang, The major acidic fibroblast growth factor (aFGF)-stimulated phosphoprotein from bovine liver plasma membranes has aFGF-stimulated kinase, autoadenylation, and alkaline nucleotide phosphodiesterase activities, J. Biol. Chem. 268 (1993) 27318-27326.

[18] S.I. Belli, F.A. Mercuri, A. Sali, J.W. Goding, Autophosphorylation of PC-1 (alkaline phosphodiesterase I/nucleotide pyrophosphatase) and analysis of the active site, Eur. J. Biochem. 228 (1995) 669-676.

[19] M. Uriarte, W. Stalmans, S. Hickman, M. Bollen, Regulation of purified hepatic PC-1 (phosphodiesterase-I/nucleotide pyrophosphatase) by threonine auto(de)phosphorylation and by binding of acidic fibroblast growth factor, Biochem. J. 306 (1995) 271-277.

[20] T. Clair, H.Y. Lee, L.A. Liotta, M.L. Stracke, Autotaxin is an ectoenzyme possessing 5'-nucleotide phosphodiesterase/ATP pyrophosphatase and ATPase activities, J. Biol. Chem. 272 (1997) 996-1001.

[21] S.I. Belli, I.R. van Driel, J.W. Goding, Identification and characterization of a soluble form of the plasma cell membrane glycoprotein PC-1 (5'-nucleotide phosphodiesterase), Eur. J. Biochem. 217 (1993) $421-428$.

[22] N.R. Meerson, V. Bello, J.L. Delaunay, T.A. Slimane, D. Delautier, C. Lenoir, G. Trugnan, M. Maurice, Intracellular traffic of the ectonucleotide pyrophosphatase/phosphodiesterase NPP3 to the apical plasma membrane of MDCK and Caco-2 cells: apical targeting occurs in the absence of N-glycosylation, J. Cell Sci. 113 (2000) 4193-4202.

[23] M.L. Stracke, A. Arestad, M. Levine, H.C. Krutzsch, L.A. Liotta, Autotaxin is an N-linked glycoprotein but the sugar moieties are not needed for its stimulation of cellular motility, Melanoma Res. 5 (1995) 203-209.

[24] M.L. Stracke, H.C. Krutzsch, E.J. Unsworth, A. Arestad, V. Cioce,
E. Schiffmann, L.A. Liotta, Identification, purification, and partial sequence analysis of autotaxin, a novel motility-stimulation protein, J. Biol. Chem. 267 (1992) 2524-2529.

[25] J. Murata, H.Y. Lee, T. Clair, H.C. Krutzsch, A. Arestad, M.E. Sobel, L.A. Liotta, M.L. Stracke, cDNA cloning of the human tumor motility-stimulating protein, Autotaxin, reveals homology with phosphodiesterases, J. Biol. Chem. 269 (1994) 30479-30484.

[26] N.R. Meerson, D. Delautier, A.M. Durand-Schneider, A. Moreau, M.L. Schilsky, I. Sternlieb, G. Feldmann, M. Maurice, Identification of B10, an alkaline phosphodiesterase of the apical plasma membrane of hepatocytes and biliary cells, in rat serum: increased levels following bile duct ligation and during the development of cholangiocarcinoma, Hepatology 27 (1997) 563-568.

[27] L. Frittitta, S. Camastra, R. Baratta, B.V. Costanzo, M. D'Adamo, S. Graci, D. Spampinato, B.A. Maddux, R. Vigneri, E. Ferrannini, V. Trischitta, A soluble PC-1 circulates in human plasma: relationship with insulin resistance and associated abnormalities, J. Clin. Endocrinol. Metab. 84 (1999) 3620-3625.

[28] A.R. Harahap, J.W. Goding, Distribution of the murine plasma cell antigen PC-1 in non-lymphoid tissues, J. Immunol. 141 (1988) $2317-2320$.

[29] K. Johnson, S. Hashimoto, M. Lotz, K. Pritzker, J. Goding, R. Terkeltaub, Up-regulated expression of the phosphodiesterase nucleotide pyrophosphatase family member PC-1 is a marker and pathogenic factor for knee meniscal cartilage matrix calcification, Arthritis Rheum. 5 (2001) 1071-1081.

[30] S. Blass-Kampmann, A. Kindler-Röhrborn, H. Deissler, D. D’Urso, M.F. Rajewsky, In vitro differentiation of neural progenitor cells from prenatal rat brain: common cell surface glycoprotein on three glial cell subsets, J. Neurosci. Res. 48 (1997) 95-111.

[31] T. Takahashi, L.J. Old, E.A. Boyse, Surface alloantigens of plasma cells, J. Exp. Med. 131 (1970) 1325-1341.

[32] P. Deterre, L. Gelman, H. Gary-Gouy, C. Arrieumerlou, V. Berthelier, J.M. Tixier, S. Ktorza, J. Goding, C. Schmitt, G. Bismuth, Coordinated regulation in human $\mathrm{T}$ cells of nucleotide-hydrolyzing ecto-enzymatic activities, including CD38 and PC-1, J. Immunol. 157 (1996) 1381-1388.

[33] T. Yano, I. Funakoshi, I. Yamashina, Purification and properties of nucleotide pyrophosphatase from human placenta, J. Biochem. 98 (1985) 1097-1107.

[34] T. Yano, K. Horie, R. Kanamoto, H. Kitagawa, I. Funakoshi, I. Yamashina, Immunoaffinity purification and characterization of nucleotide pyrophosphatase from human placenta, Biochem. Biophys. Res. Commun. 147 (1987) 1061-1069.

[35] I. Funakoshi, H. Kato, K. Horie, T. Yano, Y. Hori, H. Kobayashi, T. Inoue, H. Suzuki, S. Fukui, M. Tsukahara, Molecular cloning of cDNAs for human fibroblast nucleotide pyrophosphatase, Arch. Biochem. Biophys. 295 (1992) 180-187.

[36] R. Huang, M. Rosenbach, R. Vaughn, D. Provvedini, N. Rebbe, S. Hickman, J. Goding, R. Terkeltaub, Expression of the murine plasma cell nucleotide pyrophosphohydrolase PC-1 is shared by human liver, bone, and cartilage cells, J. Clin. Invest. 94 (1994) 560-567.

[37] P. Jin-Hua, J.W. Goding, H. Nakamura, K. Sano, Molecular cloning and chromosomal localization of PD-1beta (PNDP3), a new member of the human phosphodiesterase I genes, Genomics 45 (1997) $412-415$.

[38] B. Grobben, K. Anciaux, D. Roymans, C. Stefan, M. Bollen, E. Esmans, H. Slegers, An ecto-nucleotide pyrophosphatase is one of the main enzymes involved in the extracellular metabolism of ATP in rat C6 glioma, J. Neurochem. 72 (1999) 826-834.

[39] H.Y. Lee, J. Murata, T. Clair, M.H. Polymeropoulos, R. Torres, R.E. Manrow, L.A. Liotta, M.L. Stracke, Cloning, chromosomal localization, and tissue expression of autotaxin from human teratocarcinoma cells, Biochem. Biophys. Res. Commun. 218 (1996) 714-719.

[40] B. Fuss, H. Baba, T. Phan, V.K. Tuohy, W.B. Macklin, Phosphodiesterase I, a novel adhesion molecule and/or cytokine involved in oligodendrocyte function, J. Neurosci. 17 (1997) 9095-9103. 
[41] D. Bächner, M. Ahrens, D. Schroder, A. Hoffmann, J. Lauber, N. Betat, P. Steinert, L. Flohe, G. Gross, Bmp-2 downstream targets in mesenchymal development identified by substractive cloning from recombinant mesenchymal progenitors (C3H10T1/2), Dev. Dyn. 213 (1998) 398-411.

[42] H. Kawagoe, O. Soma, J. Goji, N. Nishimura, M. Narita, J. Inazawa, H. Nakamura, K. Sano, Molecular cloning and chromosomal assignment of the human brain-type phosphodiesterase I/nucleotide pyrophosphatase gene (PDNP2), Genomics 30 (1995) 380-384.

[43] H.J. Bühring, P.J. Simmons, M. Pudney, R. Muller, D. Jarrossay, A. van Agthoven, M. Willheim, W. Brugger, P. Valent, L. Kanz, The monoclonal antibody 97A6 defines a novel surface antigen expressed on human basophils and their multipotent and unipotent progenitors, Blood 94 (1999) 2343-2356.

[44] H.J. Bühring, M. Seiffert, C. Giesert, A. Marxer, L. Kanz, P. Valent K. Sano, The basophil activation marker defined by antibody 97A6 is identical to the ectonucleotide pyrophosphatase/phosphodiesterase 3, Blood 97 (2001) 3303-3305.

[45] P. Vollmayer, M. Koch, N. Braun, P. Heine, J. Servos, E. Israr, B. Kegel, H. Zimmermann, Multiple ecto-nucleotidases in PC12 cells: identification and cellular distribution after heterologous expression, J. Neurochem. 78 (2001) 1019-1028.

[46] M.F. Buckley, K.A. Loveland, W.J. McKinstry, O.M. Garson, J.W. Goding, Plasma cell membrane glycoprotein PC-1. cDNA cloning of the human molecule, amino acid sequence, and chromosomal location, J. Biol. Chem. 265 (1990) 17506-17511.

[47] M.J. Hilton, L. Gutiérrez, L. Zhang, P.A. Moreno, M. Reddy, N. Brown, Y. Tan, A. Hill, D.E. Wells, An integrated physical map of $8 \mathrm{q} 22-\mathrm{q} 24$ : use in positional cloning and deletion analysis of Langer-Giedion syndrome, Genomics 71 (2001) 192-199.

[48] M.F. Buckley, J.W. Goding, Plasma cell membrane glycoprotein gene Pca-1 (alkaline phosphodiesterase I) is linked to the protooncogene Myb on mouse chromosome 10, Immunogenetics 36 (1992) 199-201.

[49] J.H. Piao, Y. Matsuda, H. Nakamura, K. Sano, Assignment of Pdnp2, the gene encoding phosphodiesterase I/nucleotide pyrophosphatase 2, to mouse chromosome 15D2, Cytogenet. Cell Genet. 87 (1999) 172-174

[50] B.U. Koelsch, S. Stadge, H. Deissler, M.F. Rajewsky, Assignment of the gene for gp $130^{\mathrm{RB} 13-6}$ (Pdnpno) to rat chromosome band $1 \mathrm{p} 12$ by in situ hybridization, Cytogenet. Cell Genet. 73 (1996) 228.

[51] M. Lotz, F. Rosen, G. McCabe, J. Quach, F. Blanco, J. Dudler, J. Solan, J. Goding, J.E. Seegmiller, R. Terkeltaub, Interleukin $1 \beta$ suppresses transforming growth factor-induced inorganic pyrophosphate $(\mathrm{PPi})$ production and expression of the PPi-generating enzyme PC-1 in human chondrocytes, Proc. Natl. Acad. Sci. U. S. A. 92 (1994) 10364-10368.

[52] J.L. Solan, L.J. Deftos, J.W. Goding, R.A. Terkeltaub, Expression of the nucleoside triphosphate pyrophosphohydrolase PC-1 is induced by basic fibroblast growth factor (bFGF) and modulated by activation of the protein kinase A and $\mathrm{C}$ pathways in osteoblast-like osteosarcoma cells, J. Bone Miner. Res. 11 (1996) 183-192.

[53] M. Bitzer, G. von Gersdorff, D. Liang, A. Dominguez-Rosales, A.A. Beg, M. Rojkind, E.P. Böttinger, A mechanism of suppression of TGF- $3 /$ SMAD signaling by NF-kappa B/RelA, Genes Dev. 14 (2000) 187-197

[54] F. Verrecchia, C. Tacheau, E.F. Wagner, A. Mauviel, A central role for the Jun-N-terminal kinase pathway in mediating the antagonistic activity of pro-inflammatory cytokines against transforming growth factor-beta-driven Smad-specific gene expression, J. Biol. Chem. 278 (2002) 1585-1593.

[55] D. Bächer, M. Ahrens, N. Betat, D. Schöder, G. Gross, Developmental expression analysis of murine autotaxin (ATX), Mech. Dev. 84 (1999) $121-125$.

[56] H. Cheon, S.J. Yu, D.H. Yoo, I.J. Chae, G.G. Song, J. Sohn, Increase expression of pro-inflammatory cytokines and metalloproteinase- 1 by TGF- $\beta 1$ in synovial fibroblasts from rheumatoid ar- thritis and normal individuals, Clin. Exp. Immunol. 127 (2002) $548-553$

[57] A.N. Santos, D. Riemann, A.N. Santos, A. Kehlen, K. Thiele, J. Langner, Treatment of fibroblast-like synoviocytes with INF- $\gamma$ results in the down-regulation of autotaxin mRNA, Biochem. Biophys. Res. Commun. 229 (1996) 419-424.

[58] A. Kehlen, R. Lauterbach, A.N. Santos, K. Thiele, U. Kabisch, E. Weber, D. Riemann, J. Langner, IL-1beta- and IL-4-induced downregulation of autotaxin $\mathrm{mRNA}$ and $\mathrm{PC}-1$ in fibroblast-like synoviocytes of patients with rheumatoid arthritis (RA), Clin. Exp. Immunol. 123 (2001) 147-154.

[59] L. Ulloa, J. Doody, J. Massagué, Inhibition of transforming growth factor- $\beta /$ SMAD signalling by the interferon- $\gamma /$ STAT pathway, Nature 397 (1999) 710-713.

[60] P.S. Cohen, J.J. Letterio, C. Gaetano, J. Chan, K. Matsumoto, M.B. Sporn, C.J. Thiele, Induction of transforming growth factor beta 1 and its receptors during all- trans-retinoic acid (RA) treatment of RA-responsive human neuroblastoma cell lines, Cancer Res. 55 (1995) 2380-2386.

[61] J. Dufner-Beattie, R.S. Lemons, A. Thorburn, Retinoic acid-induced expression of autotaxin in N-Myc-amplified neuroblastoma cells, Mol. Carcinog. 30 (2001) 181-189.

[62] D.A. Tice, W. Szeto, I. Soloviev, B. Rubinfeld, S.E. Fong, D.L. Dugger, J. Winer, P.M. Williams, D. Wieand, V. Smith, R.H. Schwall, D. Pennica, P. Polakis, Synergistic induction of tumor antigens by Wnt-1 signaling and retinoic acid revealed by gene expression profiling, J. Biol. Chem. 277 (2002) 14329-14335.

[63] A. Atfi, S. Djelloul, E. Chastre, R. Davis, C. Gespach, Evidence for a role of Rho-like GTPases and stress-activated protein kinase/c-Jun $\mathrm{N}$-terminal kinase (SAPK/JNK) in transforming growth factor betamediated signaling, J. Biol. Chem. 272 (1997) 1429-1432.

[64] S. Wolter, J.F. Mushinski, A.M. Saboori, K. Resch, M. Kracht, Inducible expression of a constitutively active mutant of mitogen-activated protein kinase kinase 7 specifically activates c-JUN NH2-terminal protein kinase, alters expression of at least nine genes, and inhibits cell proliferation, J. Biol. Chem. 277 (2002) 3576-3584.

[65] R. Kettenhofen, M.K. Meyer zu Brickwedde, Y. Ko, H. Vetter, A. Sachinidis, Identification of a phosphodiesterase I/nucleotide pyrophosphatase-related gene mRNA in rat vascular smooth muscle cells by the differential display approach, J. Mol. Biol. 279 (1998) 323-329.

[66] M. Kretzschmar, J. Doody, I. Timokhina, J. Massagué, A mechanism of repression of TGF- $\beta /$ Smad signaling by oncogenic Ras, Genes Dev. 13 (1999) 804-816.

[67] L. Voisin, S. Foisy, E. Giasson, C. Lambert, P. Moreau, S. Meloche, EGF receptor transactivation is obligatory for protein synthesis stimulation by $\mathrm{G}$ protein-coupled receptors, Am. J. Physiol. Cell Physiol. 283 (2002) C446-C455.

[68] J.W. Rachow, Inorganic pyrophosphate metabolism in arthritis, Rheum. Dis. Clin. North Am. 14 (1988) 289-302.

[69] R.A. Terkeltaub, Inorganic pyrophosphate generation and disposition in pathophysiology, Am. J. Physiol. Cell Physiol. 281 (2001) $\mathrm{C} 1-\mathrm{C} 11$.

[70] S.A. Siegel, C.F. Hummel, R.P. Carty, The role of nucleoside triphosphate pyrophosphohydrolase is in vitro nucleoside triphosphatedependent matrix vesicle calcification, J. Biol. Chem. 258 (1983) $8601-8607$

[71] K. Johnson, A. Moffa, Y. Chen, K. Pritzker, J. Goding, R. Terkeltaub, Matrix vesicle plasma cell membrane glycoprotein-1 regulates mineralization by murine osteoblastic MC3T3 cells, J. Bone Miner. Res. 14 (1999) 883-892.

[72] H.C. Anderson, Molecular biology of matrix vesicles, Clin. Orthop. 314 (1995) 266-280.

[73] S.Y. Ali, Matrix formation and mineralization in bone, in: C.C. Whitehead (Ed.), Bone Biology and Skeletal Disorders, Carfax/ Abingdon, London, 1992, pp. 19-38. 
[74] H.C. Anderson, Mechanisms of pathological calcification, Rheum. Dis. Clin. North Am. 14 (1988) 303-319.

[75] B.O. Oyajobi, R.G. Russell, A.M. Caswell, Modulation of ectonucleoside triphosphate pyrophosphatase activity of human osteoblast-like bone cells by 1 alpha, 25-dihydroxyvitamin D3, 24R, 25-dihydroxyvitamin D3, parathyroid hormone, and dexamethasone, J. Bone Miner. Res. 9 (1994) 1259-1266.

[76] K. Johnson, S. Vaingankar, Y. Chen, A. Moffa, M.B. Goldring, K. Sano, P. Jin-Hua, A. Sali, J. Goding, R. Terkeltaub, Differential mechanisms of inorganic pyrophosphate production by plasma cell membrane glycoprotein-1 and B10 in chondrocytes, Arthritis Rheum. 42 (1999) 1986-1997.

[77] L.M. Ryan, D.J. McCarty, Understanding inorganic pyrophosphate metabolism: toward prevention of calcium pyrophosphatse dihydrate crystal deposition, Ann. Rheum. Dis. 54 (1995) 939-941.

[78] F. Rosen, G. McCabe, J. Quach, J. Solan, R. Terkeltaub, J.E. Seegmiller, M. Lotz, Differential effects of aging on human chondrocyte responses to transforming growth factor $\beta$, Arthritis Rheum. 40 (1997) $1275-1281$.

[79] I. Masuda, J. Hirose, Animal models of pathological calcification, Curr. Opin. Rheumatol. 14 (2002) 287-291.

[80] A.K. Rosenthal, H.S. Cheung, L.M. Ryan, Transforming growth factor- $\beta 1$ stimulates inorganic pyrophosphate elaboration by porcine cartilage, Arthritis Rheum. 34 (1991) 904-911.

[81] B.D. Boyan, Z. Schwartz, S. Park-Snyder, D.D. Dean, F. Yang, D. Twardzik, L.F. Bonewald, Latent transforming growth factor-beta is produced by chondrocytes and activated by extracellular matrix vesicles upon exposure to $1,25-(\mathrm{OH})_{2} \mathrm{D}_{3}$, J. Biol. Chem. 269 (1994) 28374-28381.

[82] L. Hessle, K.A. Johnson, H.C. Anderson, S. Narisawa, A. Sali, J.W. Goding, R. Terkeltaub, J.L. Millan, Tissue-non specific alkaline phosphatase and plasma cell membrane glycoprotein-1 are central antagonistic regulators of bone mineralization, Proc. Natl. Acad. Sci. U. S. A. 99 (2002) 9445-9449.

[83] J.A. Eastgate, J.A. Symons, N.C. Wood, F.M. Grinlinton, F.S. di Giovine, G.W. Duff, Correlation of plasma interleukin 1 levels with disease activity in rheumatoid arthritis, Lancet 2 (1988) 706-709.

[84] M. Pattrick, E. Hamilton, J. Hornby, M. Doherty, Synovial fluid pyrophosphate and nucleoside triphosphate pyrophosphatase: comparison between normal and diseased and between inflamed and non-inflamed joints, Ann. Rheum. Dis. 50 (1991) 214-218.

[85] J. Tenenbauw, O. Muniz, H.R. Schumacher, A.E. Good, D.S. Howell, Comparison of phosphohydrolase activities from articular cartilage in calcium pyrophosphate deposition disease and primary osteoarthritis, Arhritis Rheum. 24 (1981) 492-500.

[86] L.M. Ryan, R.L. Wortmann, B. Karas, M.P. Lynch, D.J. McCarthy, Pyrophosphohydrolase activity and inorganic pyrophosphate content of cultured human skin fibroblasts, J. Clin. Invest. 77 (1986) $1689-1693$.

[87] R.L. Wortmann, L.M. Ryan, B. Karas, D.J. McCarthy, Ecto-nucleoside triphosphate pyrophosphohydrolase activity and calcium pyrophosphate dihydrate crystal deposition disease, Adv. Exp. Med. Biol. 195 (1986) $153-156$.

[88] J.W. Rachow, L.M. Ryan, D.J. McCarty, P.C. Halverson, Synovial fluid inorganic pyrophosphate concentration and nucleotide pyrophosphohydrolase activity in basic calcium phosphate deposition arthropathy and Milwaukee shoulder syndrome, Arthritis Rheum. 31 (1988) 408-413.

[89] L.M. Ryan, I.V. Kurup, B.A. Derfus, V.M. Kushnaryov, ATP-induced chondrocalcinosis, Arthritis Rheum. 35 (1992) 1520-1525.

[90] A. Okawa, I. Nakamura, S. Goto, H. Moriya, Y. Nakamura, S. Ikegawa, Mutation in Npps in a mouse model of ossification of the posterior longitudinal ligament of the spine, Nat. Genet. 19 (1998) 271-273.

[91] A. Sali, J.M. Favarolo, R. Terkeltaub, J.W. Goding, Germline deletion of the nucleoside triphosphate pyrophosphohydrolase (NTPPPH) plasma cell membrane glycoprotein (PC-1) produces abnormal calci- fication of peri-articular tissues, in: L. Vanduffel, R. Lemmens (Eds.), Ecto-ATPases and Related Ectonucleotidases, Shaker Publishing, Maastricht, The Netherlands, 1999, pp. 267-282.

[92] A. Terakado, M. Tagawa, S. Goto, M. Yamazaki, H. Moriya, S. Fujimura, Elevation of alkaline phosphatase activity induced by parathyroid hormone in osteoblast-like cells from the spinal hyperostotic mouse TWY (twy/twy), Calcif. Tissue Int. 56 (1995) $135-139$.

[93] F. Rutsch, S. Vaingankar, K. Johnson, I. Goldfine, B. Maddux, P. Schauerte, H. Kalhoff, K. Sano, A. Boisvert, A. Superti-Furga, R. Terkeltaub, PC-1 nucleoside triphosphate pyrophosphohydrolase deficiency in iodopathic infantile arterial calcification, Am. J. Pathol. 158 (2001) 543-554.

[94] N. Tsuyama, Ossification of the posterior longitudinal ligament of the spine, Clin. Orthop. 184 (1984) 71-84.

[95] I. Nakamura, S. Ikegawa, S. Okawa, S. Okuda, Y. Koshizuka, H. Kawaguchi, K. Nakamura, T. Koyama, S. Goto, J. Toguchida, M. Matsushita, T. Ochi, K. Takaoka, Y. Nakamura, Association of the human NPPS gene with ossification of the posterior longitudinal ligament of the spine (OPLL), Hum. Genet. 104 (1999) 492-497.

[96] M. Yamazaki, H. Moriya, S. Goto, Y. Saitou, K. Arai, Y. Nagai, Increased type XI collagen expression in the spinal hyperostotic mouse (TWY/TWY), Calcif. Tissue Int. 48 (1991) 182-189.

[97] H. Baba, N. Furuswa, M. Fukuda, Y. Maezawa, S. Imura, N. Kawahara, K. Nakahashi, K. Tomita, Potential role of streptozotocin in enhancing ossification of the posterior logitudinal ligament of the cervical spine in the hereditary spinal hyperostotic mouse (twy/twy), Eur. J. Histochem. 41 (1997) 191-202.

[98] A.M. Ho, M.D. Johnson, D.M. Kingsley, Role of the mouse ank gene in control of tissue calcification and arthritis, Science 289 (2000) 265-270.

[99] A. Pendleton, M.D. Johnson, A. Hughes, K.A. Gurley, A.M. Ho, M. Doherty, J. Dixey, P. Gillet, D. Loeuille, R. McGrath, A. Reginato, R. Shiang, G. Wright, P. Netter, C. Williams, D.M. Kingsley, Mutations in ANKH cause chondrocalcinosis, Am. J. Hum. Genet. 71 (2002) $933-940$.

[100] R. Terkeltaub, M. Rosenbach, F. Fong, J. Goding, Causal link between nucleotide pyrophosphatase overactivity and increased intracellular inorganic pyrophosphate generation demonstrated by transfection of cultured fibroblasts and osteoblasts with plasma membrane glycoprotein-1. Relevance to calcium pyrophosphate dihydrate deposition disease, Arthritis Rheum. 37 (1994) 934-941.

[101] J.T. Neary, M.D. Norenberg, Signaling by extracellular ATP: physiological and pathological considerations in neuronal-astrocytic interactions, Prog. Brain Res. 94 (1992) 145-151.

[102] G. Burnstock, Physiological and pathological roles of purines: an update, Drug Dev. Res. 28 (1993) 195-206.

[103] F.A. Edwards, A.J. Gibb, ATP-a fast neurotransmitter, FEBS Lett. 325 (1993) 86-89.

[104] D.K.J.E. Von Lubitz, Adenosine and cerebral ischemia: therapeutic future or death of a brave concept? Eur. J. Pharmacol. 365 (1999) $9-25$.

[105] G. Burnstock, M. Williams, P2 purinergic receptors: modulation of cell function and therapeutic potential, J. Pharmacol. Exp. Ther. 295 (2000) $862-869$.

[106] S. Latini, F. Pedata, Adenosine in the central nervous system: release mechanisms and extracellular concentrations, J. Neurochem. 79 (2001) $463-484$.

[107] S. Ohkubo, K. Kumazawa, K. Sagawa, J. Kimura, I. Matsuoka, Beta, gamma-methylene ATP-induced cAMP formation in C6Bu-1 cells: involvement of local metabolism and subsequent stimulation of adenosine A2B receptor, J. Neurochem. 76 (2001) 872-880.

[108] G. Burnstock, Purinergic signaling and vascular cell proliferation and death, Arterioscler. Thromb. Vasc. Biol. 22 (2002) 364-373.

[109] P. Di Iorio, S. Kleywegt, R. Ciccarelli, U. Traversa, C.M. Andrew, C.E. Crocker, E.S. Werstiuk, M.P. Rathbone, Mechanisms of apop- 
tosis induced by purine nucleosides in astrocytes, Glia 38 (2002) $179-190$.

[110] S.M. Schrier, B.I. Florea, G.I. Mulder, J.F. Nagelkerke, A.P. Ijzerman, Apoptosis induced by extracellular ATP in mouse neuroblastoma cell line N1E-115: studies on involvement of P2 receptors and adenosine, Biochem. Pharmacol. 63 (2002) 1119-1126.

[111] C.M. Anderson, F.E. Parkinson, Potential signalling roles for UTP and UDP: sources, regulation and release of uracil nucleotides, Trends Pharmacol. Sci. 18 (1997) 387-392.

[112] K.T. Harden, E.R. Lazarowski, Release of ATP and UTP from astrocytoma cells, Prog. Brain Res. 120 (1999) 135-143.

[113] E.R. Lazarowski, R.C. Boucher, K.T. Harden, Constitutive release of ATP and evidence for major contribution of ecto-nucleotide pyrophosphatase and nucleoside diphosphokinase to extracellular nucleotide concentrations, J. Biol. Chem. 275 (2000) 31061-31068.

[114] P. Bodin, G. Burnstock, Purinergic signalling: ATP release, Neurochem. Res. 26 (2001) 959-969.

[115] H. Zimmermann, Biochemistry, localization and functional roles of ecto-nucleotidases in the nervous system, Prog. Neurobiol. 49 (1996) $589-618$.

[116] P. Sneddon, T.D. Westfall, L.D. Todorov, S. Mihaylova-Todorova, D.P. Westfall, C. Kennedy, Modulation of purinergic neurotransmission, Prog. Brain Res. 120 (1999) 11-20.

[117] G.A. Weisman, K.D. Lustig, E. Lane, N. Huang, I. Belzer, I. Friedberg, Growth inhibition of transformed mouse fibroblasts by adenosine occurs via generation of extracellular adenosine, J. Biol. Chem. 263 (1988) 12367-12372.

[118] M.P. Abbrachio, M.J. Saffrey, V. Höpker, G. Burnstock, Modulation of astroglial cell proliferation by analogues of adenosine and ATP in primary cultures of rat striatum, Neuroscience 59 (1994) 67-76.

[119] S. Harper, T.E. Webb, S.J. Charlton, L.L. Ng, M.R. Boarder, Evidence that $\mathrm{P}_{2} \mathrm{Y}_{4}$ nucleotide receptors are involved in the regulation of rat aortic smooth muscle cells by UTP and ATP, Br. J. Pharmacol. 124 (1998) 703-710.

[120] S.P. Seetulsingh-Goorah, B.W. Steward, Growth inhibition of HL-60 cells by extracellular ATP: concentration-dependent involvement of a P2 receptor and adenosine generation, Biochem. Biophys. Res. Commun. 250 (1998) 390-396.

[121] P. Claes, B. Grobben, K. Van Kolen, D. Roymans, H. Slegers, P2 $\mathrm{Y}_{\mathrm{AC}}^{-}$ -receptor agonists enhance the proliferation of rat $\mathrm{C} 6$ glioma cells through activation of the p42/44 mitogen-activated protein kinase, Br. J. Pharmacol. 134 (2001) 402-408.

[122] P. Fishman, S.B. Baryehuda, L. Vagman, Adenosine and low molecular weight factors released by muscle cells inhibit tumor cell growth, Cancer Res. 58 (1998) 3181-3187.

[123] G. Ohana, S. Bar-Yehuda, F. Barer, P. Fishman, Differential effect of adenosine on tumor and normal cell growth: focus on the A3 adenosine receptor, J. Cell. Physiol. 186 (2001) 19-23.

[124] H. Zimmermann, Extracellular hydrolysis of ATP and other nucleotides, Naunyn-Schmiedeberg's Arch. Pharmacol. 362 (2000) 299-309.

[125] B. Grobben, P. Claes, D. Roymans, E.L. Esmans, H. Van Onckelen, H. Slegers, Ecto-nucleotide pyrophosphatase modulates the purinoceptor-mediated signal transduction and is inhibited by purinoceptor antagonists, Br. J. Pharmacol. 130 (2000) 139-145.

[126] B. Grobben, P. Claes, K. Van Kolen, D. Roymans, P. Fransen, S.U. Sys, H. Slegers, Agonists of the $\mathrm{P}^{2} \mathrm{Y}_{\mathrm{AC}}^{-}$receptor activate MAP kinase by a ras-independent pathway in rat $\mathrm{C} 6$ glioma, J. Neurochem. 78 (2001) 1325-1338.

[127] R.A. North, A. Surprenant, Pharmacology of cloned P2X receptors, Annu. Rev. Pharmacol. Toxicol. 40 (2000) 563-580.

[128] I. von Kügelgen, A. Wetter, Molecular pharmacology of P2Y-receptors, Naunyn-Schmiedeberg's Arch. Pharmacol. 362 (2000) $310-323$.

[129] F.A. Redegeld, C.C. Caldwell, M.V. Sitkovsky, Ecto-protein kinase: ecto-domain phosphorylation as a novel target for pharmacological manipulation? Trends Pharmacol. Sci. 20 (1999) 453-459.
[130] S.C. Chow, G.E.N. Kass, S. Orrenius, Purines and their role in apoptosis, Neuropharmacology 36 (1997) 1149-1156.

[131] Z. Zhao, T. Kapoian, M. Shepard, E.A. Lianos, Adenosine-induced apoptosis in glomerular mesangial cells, Kidney Int. 61 (2002) $1276-1285$.

[132] K.A. Rudolphi, P. Schubert, F.E. Parkinson, B.B. Fredholm, Neuroprotective role of adenosine in cerebral ischemia, Trends Pharmacol. Sci. 13 (1992) 439-445.

[133] M. Che, Z. Gatmaitan, I.M. Arias, Ectonucleotidases, purine nucleoside transporter, and function of the bile canalicular plasma membrane of the hepatocyte, FASEB J. 11 (1997) 101-108.

[134] R.S. Chari, S.M. Schutz, J.E. Haebig, G.H. Shimokura, P.B. Cotton, J.G. Fitz, W.C. Meyers, Adenosine nucleotides in bile, Am. J. Physiol. 270 (1996) G246-G252.

[135] T. Schlenker, J.M. Romac, A.I. Sharara, R.M. Roman, S.J. Kim, N. LaRusso, R.A. Liddle, J.G. Fitz, Regulation of bile secretion through apical purinergic receptors in cultured rat cholangiocytes, Am. J. Physiol. 273 (1997) G1108-G1117.

[136] J.C. Byrd, F.J. Fearney, Y.S. Kim, Rat intestinal nucleotide-sugar pyrophosphatase. Localization, partial purification, and substrate specificity, J. Biol. Chem. 260 (1985) 7474-7480.

[137] G. Zhang, Z. Zhao, S. Xu, L. Ni, X. Wang, Expression of autotaxin mRNA in human hepatocelluar carcinoma, Chin. Med. J. 112 (1999) $330-332$.

[138] H. Kawagoe, M.L. Stracke, H. Nakamura, K. Sano, Expression and transcriptional regulation of the PD-I $\alpha /$ autotaxin gene in neuroblastoma, Cancer Res. 57 (1997) 2516-2521.

[139] P.T. Mulvaney, M.L. Stracke, S.W. Nam, E. Woodhouse, M. O'Keefe, T. Clair, L.A. Liotta, R. Khaddurah-Daouk, E. Schiffmann, Cyclocreatine inhibits stimulated motility in tumor cells possessing creatine kinase, Int. J. Cancer 78 (1998) 46-52.

[140] Y. Yang, L.J. Mou, N. Liu, M.S. Tsao, Autotaxin expression in nonsmall-cell lung cancer, Am. J. Respir. Cell Mol. Biol. 21 (1999) 216-222.

[141] H.Y. Lee, T. Clair, P.T. Mulvaney, E.C. Woodhouse, S. Aznavoorian, L.A. Liotta, M.L. Stracke, Stimulation of tumor motility linked to phosphodiesterase catalytic site of autotaxin, J. Biol. Chem. 271 (1996) 24408-24412.

[142] S.W. Nam, T. Clair, C.K. Campo, H.Y. Lee, L.A. Liotta, M.L. Stracke, Autotaxin (ATX), a potent tumor mitogen, augments invasion and metastatic potential of ras-transformed cells, Oncogene 19 (2000) 241-247.

[143] S.W. Nam, T. Clair, Y.S. Kim, A. McMarlin, E. Schifmann, L.A. Liotta, M.L. Stracke, Autotaxin (NPP-2), a metastasis-enhancing motogen, is an angiogenic factor, Cancer Res. 61 (2001) 6938-6944.

[144] M. Saleh, I.D. Davis, A.F. Wilks, The paracrine role of tumourderived mIL-4 on tumour-associated endothelium, Int. J. Cancer 72 (1997) 664-672.

[145] O.V. Volpert, T. Fong, A.E. Koch, J.D. Peterson, C. Waltenbaugh, R.I. Tepper, N.P. Bouck, Inhibition of angiogenesis by interleukin 4, J. Exp. Med. 188 (1998) 1039-1046.

[146] M. Saleh, A. Wiegmans, Q. Malone, S.S. Stylli, A.H. Kaye, Effect of in situ retroviral interleukin-4 transfer on established intracranial tumors, J. Natl. Cancer Inst. 91 (1999) 438-445.

[147] C.D. Nobes, A. Hall, Rho GTPases control polarity, protrusion, and adhesion during cell movement, J. Cell Biol. 144 (1999) $1235-1244$.

[148] A. Yart, S. Roche, R. Wetzker, M. Laffargue, N. Tonks, P. Mayeux, H. Chap, P. Raynal, A function for phosphoinositide 3-kinase $\beta$ lipid products in coupling $\beta \gamma$ to ras activation in response to lysophosphatidic acid, J. Biol. Chem. 277 (2002) 21167-21178.

[149] H.Y. Lee, G.U. Bae, I.D. Jung, J.S. Lee, Y.K. Kim, S.H. Noh, M.L. Stracke, C.G. Park, H.W. Lee, J.W. Han, Autotaxin promotes motility via $G$ protein-coupled phosphoinositide 3-kinase $\gamma$ in human melanoma cells, FEBS Lett. 515 (2002) 137-140.

[150] H. Deissler, S. Blass-Kampmann, E. Bruyneel, M. Mareel, M.F. Rajewsky, Neural cell surface differentiation antigen gp $130^{\mathrm{RB} 13-6}$ 
induces fibroblasts and glioma cells to express astroglial proteins and invasive properties, FASEB J. 13 (1999) 657-666.

[151] A.M. Durand-Schneider, M. Maurice, M. Dumont, G. Feldman, Effect of colchicine and phalloidin on the distribution of three plasma membrane antigens in rat hepatocytes: comparison with bile duct ligation, Hepatology 7 (1987) 1239-1248.

[152] J.Y. Scoazec, A. Moreau, M. Maurice, N. Hassan, G. Feldmann, Detection of a biliary cell membrane glycoprotein in the serum of cholangiocarcinoma-bearing rats, Lab. Invest. 62 (1990) 459-466.

[153] M. Maurice, M.J. Schell, B. Lardeux, A.L. Hubbard, Biosynthesis and intracellular transport of a bile canalicular plasma membrane protein: studies in vivo and in the perfused rat liver, Hepatology 19 (1994) 648-655.

[154] W.T. Garvey, M.J. Birnbaum, Cellular insulin action and insulin resistance, Bailliere's Clin. Endocrinol. Metab. 7 (1993) 785-873.

[155] A. Krook, S. O'Rahilly, Mutant insulin receptors in syndromes of insulin resistance, Bailliere's Clin. Endocrinol. Metab. 10 (1996) $97-122$.

[156] D.J. Withers, M. White, Perspective: the insulin signaling sytem-a common link in the pathogenesis of type 2 diabetes, Endocrinology 141 (2000) 1917-1921.

[157] D. Le Roith, Y. Zick, Recent advances in our understanding of insulin action and insulin resistance, Diabetes Care 24 (2001) $588-597$.

[158] D.E. Moller, J.S. Flier, Insulin resistance-mechanisms, syndromes, and implications, New Engl. J. Med. 325 (1991) 938-948.

[159] S.I. Taylor, Lilly lecture: molecular mechanisms of insulin resistance, Diabetes 41 (1992) 1473-1490.

[160] B.A. Maddux, P. Sbraccia, G.M. Reaven, D.E. Moller, I.D. Goldfine, Inhibitors of insulin receptor tyrosine kinase in fibroblasts from diverse patients with impaired insulin action: evidence for a novel mechanism of postreceptor insulin resistance, J. Clin. Endocrinol. Metab. 77 (1993) 73-79.

[161] B.A. Maddux, P. Sbraccia, S. Kumakura, S. Sasson, J. Youngren, A. Fisher, S. Spencer, A. Grupe, W. Henzel, T.A. Steward, G.M. Reaven, I.D. Goldfine, Membrane glycoprotein PC-1 and insulin resistance in non-insulin-dependent diabetes mellitus, Nature 373 (1995) 448-451.

[162] J.P. Whitehead, P.J. Humphreys, K. Dib, J.W. Goding, S. O'Rahilly, Expression of the putative inhibitor of the insulin receptor tyrosine kinase PC-1 in dermal fibroblasts from patients with syndromes of severe insulin resistance, Clin. Endocrinol. 47 (1997) 65-70.

[163] A. Belfiore, A. Costantino, F. Frasca, G. Pandini, R. Mineo, P. Vigneri, B. Maddux, I.D. Goldfine, R. Vigneri, Overexpression of membrane glycoprotein PC-1 in MDA-MB231 breast cancer cells is associated with inhibition of insulin receptor tyrosine kinase activity, Mol. Endocrinol. 10 (1996) 1318-1326.

[164] A. Pfeiffer, K. Middelberg-Bisping, C. Drewes, H. Schatz, Elevated plasma levels of transforming growth factor-beta 1 in NIDDM, Diabetes Care 19 (1996) 1113-1117.

[165] G. Reaven, Role of insulin resistance in human disease, Diabetes 35 (1988) 1595-1607.

[166] L. Frittitta, J. Youngren, R. Vigneri, B.A. Maddux, V. Trischitta, I.D. Goldfine, PC-1 content in skeletal muscle of non-obese, nondiabetic subjects: relationship to insulin receptor tyrosine kinase and whole body insulin sensitivity, Diabetologia 39 (1996) $1190-1195$.

[167] L. Frittitta, J.F. Youngren, P. Sbraccia, M.D. Adamo, A. Buongiorno, R. Vigneri, I.D. Goldfine, V. Trischitta, Increased adipose tissue PC1 protein content, but not tumour necrosis factor- $\alpha$ gene expression, is associated with a reduction of the whole body insulin sensitivity and insulin receptor tyrosine-kinase activity, Diabetologia 40 (1997) $282-289$.

[168] L. Frittitta, D. Spampinato, A. Solini, R. Nosadini, I.D. Goldfine, R. Vigneri, V. Trischitta, Elevated PC-1 content in cultured skin fibroblasts correlates with decreased in vivo and in vitro insulin action in nondiabetic subjects: evidence that PC-1 may be an in- trinsic factor in impaired insulin receptor signaling, Diabetes 47 (1998) 1095-1100.

[169] J.F. Youngren, B.A. Maddux, S. Sasson, P. Sbraccia, E.B. Tapscott, M.S. Swanson, G.L. Dohm, I.D. Goldfine, Skeletal muscle content of membrane glycoprotein PC-1 in obesity. Relationship to muscle glucose transport, Diabetes 45 (1996) 1324-1328.

[170] C. Pender, H.K. Ortmeyer, B.C. Hansen, I.D. Goldfine, J.F. Youngren, Elevated plasma cell membrane glycoprotein levels and diminished insulin autophosphorylation in obese, insulin-resistant rhesus monkeys, Metabolism 51 (2002) 465-470.

[171] J. Shao, P.M. Catalano, H. Yamashita, I. Ruyter, S. Smith, J. Youngren, J.E. Friedman, Decreased insulin receptor tyrosine kinase activity and plasma cell membrane glycoprotein-1 overexpression in skeletal muscle from obese women with gestational diabetes mellitus (GDM), Diabetes 49 (2000) 603-610.

[172] M. Tomazic, A. Janez, A. Sketelj, A. Kocijancic, J. Eckel, P.M. Sharma, Comparison of alterations in insulin signaling pathway in adipocytes from type II diabetic pregnant women and women with gestational diabetes mellitus, Diabetologia 45 (2002) $502-508$.

[173] V. Stefanovic, S. Antic, M. Mitic-Zlatkovic, P. Vlahovic, Reversal of increased lymphocyte PC-1 activity in patients with type 2 diabetes treated with metformin, Diabetes Metab. Res. Rev. 15 (1999) 400-404.

[174] M. Li, J.F. Youngren, V.P. Manchem, M. Kozlowski, B.B. Zhang, B.A. Maddux, I.D. Goldfine, Small molecule insulin receptor activators potentiate insulin action in insulin-resistant cells, Diabetes 50 (2001) 2323-2328.

[175] A. Pizzuti, L. Frittitta, A. Argiolas, R. Baratta, I.D. Goldfine, M. Bozzali, T. Ercolino, G. Scarlato, L. Iacoviello, R. Vigneri, V. Tassi, V. Trischitta, A polymorphism (K121Q) of the human glycoprotein PC-1 gene coding region is strongly associated with insulin resistance, Diabetes 48 (1999) 1881-1884.

[176] H.F. Gu, P. Almgren, E. Lindholm, L. Frittitta, A. Pizzuti, V. Trischitta, L.C. Groop, Association between the human glycoprotein PC-1 gene and elevated glucose and insulin levels in a paired-sibling analysis, Diabetes 49 (2000) 1601-1603.

[177] S.K. Rasmussen, S.A. Urhammer, A. Pizzuti, S.M. Achwald, C.T. Ekstrom, L. Hansen, T. Hansen, K. Borch-Johansen, L. Frittitta, V. Trischitta, O. Pedersen, The K121Q variant of the human PC-1 gene is not associated with insulin resistance or type 2 diabetes among Danish Caucasians, Diabetes 49 (2000) 1608-1611.

[178] S. De Cosmo, A. Argiolas, G. Miscio, S. Thomas, G.P. Piras, R. Trevisan, P.C. Perin, S. Bacci, L. Zucaro, M. Margaglione, L. Frittitta, A. Pizzuti, V. Tassi, G.C. Viberti, V. Trischitta, A PC-1 amino acid variant (K121Q) is associated with faster progression of renal disease in patients with type 1 diabetes and albuminuria, Diabetes 49 (2000) 521-524.

[179] L. Tarnow, N. Grarup, T. Hansen, H.H. Parving, O. Pederson, Diabetic microvasculature complications are not associated with two polymorphisms in the GLUT-1 and PC-1 genes regulating glucose metabolism in Caucasian type 1 diabetic patients, Nephrol. Dial. Transplant. 16 (2001) 1653-1656.

[180] P. Jacobsen, N. Grarup, L. Tarnow, H.H. Parving, O. Pedersen, PC-1 amino acid variant (K121Q) has no impact on progression of diabetic nephropathy in type 1 diabetic patients, Nephrol. Dial. Transplant. 17 (2002) 1408-1412.

[181] L.H. Canani, D.P. Ng, A. Smiles, J.J. Rogus, J.H. Warram, A.S Krolewski, Polymorphism in ecto-nucleotide pyrophosphatase/phosphodiesterase 1 gene (ENPP1/PC-1) and early development of advanced diabetic nephropathy in type 1 diabetes, Diabetes 51 (2002) $1188-1193$.

[182] L. Frittitta, T. Ercolino, M. Bozzali, A. Argiolas, S. Gravi, M.G. Santagati, D. Spampinato, R. Di Paolo, C. Cisternino, V. Tassi, R. Vigneri, A. Pizzuti, V. Trischitta, A cluster of three single nucleotide polymorphisms in the $3^{\prime}$-untranslated region of human glycoprotein PC-1 gene stabilizes PC-1 mRNA and is associated with 
increased PC-1 protein content and insulin resistance-related abnormalities, Diabetes 50 (2001) 1952-1955.

[183] R. Duggirala, J. Blangero, L. Almasy, R. Arya, T.D. Dyer, K.L. Williams, R.J. Leach, P. O'Connell, M.P. Stern, A major locus for fasting insulin concentrations and insulin resistance on chromosome $6 \mathrm{q}$ with strong pleiotropic effects on obesity-related phenotypes in nondiabetic Mexican Americans, Am. J. Hum. Genet. 68 (2001) $1149-1164$.

[184] C. Stefan, S. Wera, W. Stalmans, M. Bollen, The inhibition of the insulin receptor by the membrane protein PC-1 is not specific and results from the hydrolysis of ATP, Diabetes 45 (1996) 980-983.

[185] B. Özel, J.F. Youngren, J.K. Kim, I.D. Goldfine, C.K. Sung, J.H. Youn, The development of insulin resistance with high fat feeding in rats does not involve either decreased insulin receptor tyrosine kinase activity or membrane glycoprotein PC-1, Biochem. Mol. Med. 59 (1996) 174-181.

[186] J.F. Youngren, J. Paik, R.J. Barnard, Impaired insulin-receptor autophosphorylation is an early defect in fat-fed, insulin-resistant rats, J. Appl. Physiol. 91 (2001) 2240-2247.

[187] A. Grupe, J. Alleman, I.D. Goldfine, M. Sadick, T.A. Stewart, Inhibition of insulin receptor phosphorylation by PC-1 is not mediated by the hydrolysis of adenosine triphosphate or the generation of adenosine, J. Biol. Chem. 270 (1995) 22085-22088.

[188] D. Hillaire-Buys, J. Chapal, G. Bertrand, P. Petit, M.M. LoubatieresMariani, Purinergic receptors on insulin-secreting cells, Fundam. Clin. Pharmacol. 8 (1994) 117-127.

[189] L. Heseltine, J.M. Webster, R. Taylor, Adenosine effects upon insulin action on lipolysis and glucose transport in human adipocytes, Mol. Cell. Biochem. 144 (1995) 147-151.

[190] B.A. Maddux, I.D. Goldfine, Membrane glycoprotein PC-1 inhibition of insulin receptor function occurs via direct interaction with the receptor $\alpha$-subunit, Diabetes 49 (2000) 13-19.

[191] B.V. Costanzo, V. Trischitta, R. Di Paolo, D. Spampinato, A. Pizzuti, R. Vigneri, L. Frittitta, The Q allele variant $\left(\mathrm{GLN}^{121}\right)$ of membrane glycoprotein PC-1 interacts with the insulin receptor and inhibits insulin signaling more effectively than the common $\mathrm{K}$ allele variant $\left(\right.$ LYS $\left.^{121}\right)$, Diabetes 50 (2001) 831-836.

[192] C. Marino-Buslje, K. Mizuguchi, K. Siddle, T.L. Blundell, A third fibronectin type III domain in the extracellular region of the insulin receptor family, FEBS Lett. 441 (1998) 331-336.

[193] H. Sakoda, T. Ogihara, M. Anai, M. Funaki, K. Inukai, H. Katagiri, Y. Fukushima, Y. Onishi, H. Ono, Y. Yazaki, M. Kikuchi, Y. Oka, T. Asano, No correlation of plasma cell 1 overexpression with insulin resistance in diabetic rats and 3T3-L1 adipocytes, Diabetes 48 (1999) 1365-1371

[194] S. Kumakura, B.A. Maddux, C.K. Sung, Overexpression of membrane glycoprotein PC-1 can influence insulin action at a post-receptor site, J. Cell. Biochem. 68 (1998) 366-377.

[195] A.R. Saltiel, New perspectives into the molecular pathogenesis and treatment of type 2 diabetes, Cell 104 (2001) 517-529.

[196] D.J. Withers, J.S. Gutierrez, H. Towery, D.J. Burks, J.M. Ren, S. Previs, Y. Zhang, D. Bernal, S. Pons, G.I. Shulman, S. Bonner-Weir, M.F. White, Disruption of IRS-2 causes type 2 diabetes in mice, Nature 391 (1998) 900-904.

[197] I.R. van Driel, J.W. Goding, N. Koch, Plasma cell antigen PC-1 and the transferrin receptor in mouse, rat, and hamster: serologic and biochemical analysis, J. Immunol. 134 (1985) 3987-3993.

[198] Y. Oda, M.D. Kuo, S.S. Huang, J.S. Huang, The plasma cell membrane glycoprotein, $\mathrm{PC}-1$, is a threonine-specific protein kinase stimulated by acidic fibroblast growth factor, J. Biol. Chem. 266 (1991) 16791-16795.

[199] C. Stefan, R. Gijsbers, W. Stalmans, M. Bollen, Differential regulation of the expression of nucleotide pyrophosphatase/phosphodiesterase in rat liver, Biochim. Biophys. Acta 1450 (1999) 45-52.

[200] H. Zimmermann, A.R. Beaudoin, M. Bollen, J.W. Goding, G. Guidotti, T.L. Kirley, S.C. Robson, K. Sano, Proposed nomenclature for two novel nucleotide hydrolyzing enzyme families expressed on the cell surface, in: L. Vanduffel, R. Lemmens (Eds.), Ecto-ATPases and Related Ectonucleotidases, Shaker Publishing, Maastricht, The Netherlands, 2000, pp. 1-8.

[201] J. Hirose, L.M. Ryan, I. Masuda, Up-regulated expression of cartilage intermediate-layer protein and ANK in articular hyaline cartilage from patients with calcium pyrophosphate dihydrate crystal deposition disease, Arthritis Rheum. 46 (2002) 3218-3229.

[202] D. Roymans, H. Slegers, Phosphatidylinositol 3-kinases in tumor progression, Eur. J. Biochem. 268 (2001) 487-498. 